\title{
Behavioral Heterogeneity in Stock Prices
}

\author{
H. Peter Boswijk ${ }^{a}$ \\ Cars H. Hommes ${ }^{a}$ \\ Sebastiano Manzan ${ }^{b}$
}

\author{
June 2006 \\ Journal of Economic Dynamics and Control forthcoming
}

\begin{abstract}
We estimate a dynamic asset pricing model characterized by heterogeneous boundedly rational agents. The fundamental value of the risky asset is publicly available to all agents, but they have different beliefs about the persistence of deviations of stock prices from the fundamental benchmark. An evolutionary selection mechanism based on relative past profits governs the dynamics of the fractions and switching of agents between different beliefs or forecasting strategies. A strategy attracts more agents if it performed relatively well in the recent past compared to other strategies. We estimate the model to annual US stock price data from 1871 until 2003. The estimation results support the existence of two expectation regimes, and a bootstrap F-test rejects linearity in favor of our nonlinear two-type heterogeneous agent model. One regime can be characterized as a fundamentalists regime, because agents believe in mean reversion of stock prices toward the benchmark fundamental value. The second regime can be characterized as a chartist, trend following regime because agents expect the deviations from the fundamental to trend. The fractions of agents using the fundamentalists and trend following forecasting rules show substantial time variation and switching between predictors. The model offers an explanation for the recent stock prices run-up. Before the 90 s the trend following regime was active only occasionally. However, in the late 90s the trend following regime persisted and created an extraordinary deviation of stock prices from the fundamentals. Recently, the activation of the mean reversion regime has contributed to drive stock prices back closer to their fundamental valuation.
\end{abstract}

Keywords: heterogeneous expectations, stock prices, bubbles, bounded rationality, behavioral finance, evolutionary selection.

JEL codes: G12, C22.

Acknowledgments. Earlier versions of this paper were presented at the SCE-conference on Computational Economics and Finance, Seattle, June 28-30, 2003, at the 10-th WEHIA workshop in Essex, June 13-15, 2005, and at various seminars at Tilburg University, University of Amsterdam, University of Udine, University of Leicester, University of Essex, University of Kiel, Peking University and Sant'Anna School of Advanced Studies in Pisa. Stimulating discussions and helpful comments from participants, an anonymous referee and the special issue Editor Sheri Markose are gratefully acknowledged. This research has been supported by the Netherlands Organization for Scientific Research (NWO) under a NWO-MaG Pionier grant.

a CeNDEF, Department of Quantitative Economics, University of Amsterdam, Roetersstraat 11, 1018WB Amsterdam (the Netherlands). Email: h.p.boswijk@uva.nl (Boswijk), c.h.hommes@uva.nl (Hommes).

${ }^{b}$ Department of Economics, University of Leicester, University Road, Leicester LE1 7RH (United Kingdom). Email: s.manzan@le.ac.uk.

* Corresponding author. 


\section{Introduction}

Historical evidence indicates large fluctuations of stock prices compared to indicators of fundamental value. For example, the price to earnings ratio of the S\&P500 was around 5 at the beginning of the $20 \mathrm{~s}$, but more than 25 about nine years later to fall back to about 5 again by 1933. In 1995 the price/earnings ratio of the S\&P500 was close to 20, went up to more than 40 at the beginning of 2000 and then quickly declined again to about 20 by the end of 2003. Why do prices fluctuate so much compared to economic fundamentals?

This question has been strongly debated in financial economics. At the beginning of the 80s, Shiller (1981) and LeRoy and Porter (1981) claimed that the stock market exhibits excess volatility, that is, stock price fluctuations are significantly larger than movements in underlying economic fundamentals. The debate evolved in two directions. On the one hand, supporters of rational expectations and market efficiency proposed modifications and extensions of the standard theory. In contrast, another part of the literature focused on providing further empirical evidence against the efficiency of stock prices and behavioral models to explain these phenomena. The debate has recently been revived by the extraordinary surge of stock prices in the late 90s. The internet sector was the main driving force behind the unprecedented increase in market valuations. Ofek and Richardson $(2002,2003)$ estimated that in 1999 the average price-earnings ratio for internet stocks was more than 600 .

A recent overview of rational explanations based on economic fundamentals for the increase in stock prices in the late 90s is e.g. given by Heaton and Lucas (1999). They offer three reasons for the decrease of the equity premium, i.e. the difference between expected returns on the market portfolio of risky stocks and riskless bonds. A first reason is the observed increase of households' participation in the stock market. This implies spreading of equity risk among a larger population, which could explain a decrease of the risk premium required by investors. Secondly, there is evidence that investors hold more diversified portfolios compared to the past. In the 70s a large majority of investors concentrated their equity holdings on one or two stocks. More recently households have invested a large proportion of their wealth in mutual funds achieving a much better diversification of risk. Both facts justify a decrease of the required risk premium by investors. Although the wider participation seems unlikely to play an important role in the surge of stock prices in the $90 \mathrm{~s}$, the increased portfolio diversification could at least partly account for the decrease in the equity premium and the unprecedented increase in market valuations. A third, fundamental explanation for the surge of the stock market that has been 
proposed is a shift in corporate practice from paying dividends to repurchasing shares as an alternative measure to distribute cash to shareholders. In this case dividends do not measure appropriately the profitability of the asset and such a shift in corporate practice explains, at least partly, an increase in price-earnings or price-dividend ratios or equivalently a decrease of the risk premium. Further evidence on this issue is provided by Fama and French (2001).

Some recent papers attempt a quantitative evaluation of the decrease in the equity premium. Fama and French (2002) argue that, based on average dividend growth, the real risk premium has significantly decreased from $4.17 \%$ in the period $1872-1950$ to $2.5 \%$ after 1950. Jagannathan et al. (2000) go even further and, comparing the equity yield to a long-term bonds yield, reach the conclusion that the risk premium from 1970 onwards was approximately $0.7 \%$. That is, investors require almost the same return to invest in stocks and in 20 years government bonds. The explanations above indicate structural, fundamental reasons for a long-horizon tendency of the risk premium to decrease, or equivalently for an increase of the valuation of the aggregate stock market. However, to quantify the decrease in the equity premium is difficult and the estimates provided earlier are questionable. Although fundamental reasons may partly explain an increase of stock prices, the dramatic movements e.g. in the nineties are hard to interpret as an adjustment of stock prices toward a new fundamental value.

Another strand of recent literature has provided empirical evidence on market inefficiencies and proposed a behavioral explanation. Hirshleifer (2001) and Barberis and Thaler (2003) contain extensive surveys of behavioral finance and empirical results both for the cross-section of returns and for the aggregate stock market. Much attention has been paid to the continuation of short-term returns and their reversal in the long-run. This was documented both for the cross-section of returns by de Bondt and Thaler (1985), and Jegadeesh and Titman (1993) and for the aggregate market by Cutler et al. (1991). At short run horizons of 6-12 months, past winners outperform past losers, whereas at longer horizons of e.g. 3-5 years, past losers outperform past winners. A behavioral explanation of this phenomenon is that at horizons from 3 months to a year, investors underreact to news about fundamentals of a company or the economy. They slowly adjust their valuations to incorporate the news and create positive serial correlation in returns. However, in the adjustment process they drive prices too far from what is warranted by the fundamental news. This shows up in returns as negative correlation at longer horizons. Several behavioral models have been developed to explain the empirical evidence. Barberis et al. 
(1998), henceforth BSV, assume that agents are affected by psychological biases in forming expectations about future cash flows. BSV consider a model with a representative risk-neutral investor in which the true earnings process is a random walk, but investors believe that earnings are generated by one of two regimes, a mean-reverting regime and a trend regime. When confronted with positive fundamental news investors are too conservative in extrapolating the appropriate implication for the immediate asset valuation. However, they overreact to a stream of positive fundamental news because they interpret it as representative of a new regime of higher growth. The model is able to replicate the empirical observation of continuation and reversal of stock returns. Another behavioral model that aims at explaining the same stylized facts is Daniel et al. (1998), henceforth DHS. Their model stresses the importance of biases in the interpretation of private information. DHS assume that investors are overconfident and overestimate the precision of the private signal they receive about the asset pay-off. The overconfidence increases if the private signal is confirmed by public information, but decreases slowly if the private signal contrasts with public information. The model of BSV assumes that all information is public and that investors misinterpret fundamental news. In contrast, DHS emphasize overconfidence concerning private information compared to what is warranted by the public signal. These models aim to explain the continuation and reversal in the cross-section of returns. However, as suggested by Barberis and Thaler (2003), both models are also suitable to explain the aggregate market dynamics.

In this paper we consider an asset pricing model with behavioral heterogeneity and estimate the model using yearly S\&P 500 data from 1871 to 2003 . The model is a reformulation, in terms of price-to-cash flow ratios, of the asset pricing model with heterogeneous beliefs introduced by Brock and Hommes (1997, 1998). Agents are boundedly rational and have heterogeneous beliefs about future pay-offs of a risky asset. Beliefs about future cash flows are homogeneous and correct, but agents disagree on the speed the asset price will mean-revert back towards its fundamental value. A key feature of the model is the endogenous, evolutionary selection of beliefs or expectation rules based upon their relative past performance, as proposed by Brock and Hommes (1997). The estimation of our model on yearly S\&P 500 data suggests that behavioral heterogeneity is significant and that there are two different regimes, a "mean reversion" regime and a "trend following" regime. To each regime, there corresponds a different (class of) investor types: fundamentalists and trend followers. These two investor types co-exist and their fractions show considerable fluctuations over time. The mean-reversion regime corresponds to the 
situation when the market is dominated by fundamentalists, who recognize a mispricing of the asset and expect the stock price to move back towards its fundamental value. The other trend following regime represents a situation when the market is dominated by trend followers, expecting continuation of say good news in the (near) future and expect positive stock returns. Before the 90s, the trend regime is activated only occasionally and never persisted for more than two consecutive years. However, in the late 90s the fraction of investors believing in a trend increased close to one and persisted for a number of years. The prediction of an explosive growth of the stock market by trend followers was confirmed by annual returns of more than $20 \%$ for four consecutive years. These high realized yearly returns convinced many investors to also adopt the trend following belief thus reenforcing an unprecedented deviation of stock prices from their fundamental value.

The outline of the paper is as follows. Section 2 discusses some closely related literature. Section 3 describes the asset pricing model with heterogeneous beliefs and endogenous switching, while Section 4 presents the estimation results. Section 5 discusses empirical implications of our model, in particular the impulse response to a permanent positive shock to the fundamental and a simulation based prediction of how likely or unlikely high valuation ratios are in the future. Finally, Section 6 concludes and an appendix contains the details of a bootstrap F-test for linearity and discusses the robustness of our estimation with respect to time-variation in the fundamental value.

\section{Related Literature}

Our model is closely related to other work in behavioral finance, and it is useful to discuss some similarities and differences with models recently proposed in this literature. We also refer the reader to the extensive surveys on behavioral finance by Barberis and Thaler (2003) and Hirshleifer (2001) and the recent survey on dynamic heterogeneous agent models in economics and finance in Hommes (2006). Behavioral heterogeneity differentiates our model from Barberis et al. (1998) and Daniel et al. (1998) who both assume a representative agent. In contrast, we allow for the coexistence of different types of investors with heterogeneous expectations about future payoffs and evolutionary switching between different investment strategies. Disagreement in asset pricing models can arise because of two assumptions: differential information and differential interpretation. In the first case, there is an information asymmetry between one group of agents that observes a private signal and the rest of the population that has to learn the fundamental value from public information such as prices. Asymmetric information causes heterogeneous expec- 
tations among agents. Recent models of this type are Grundy and Kim (2002) and Biais et al. (2003). The second assumption is based on the fact that a public signal can be interpreted in different ways by investors. Agents use different 'models of the market' to update their subjective valuation based on the earnings news and this might lead them to hold different beliefs. Empirical evidence to support this hypothesis has been provided by Kandel and Pearson (1995). They analyze the revisions of analysts earnings forecasts around announcements. They provide significant evidence for the hypothesis that beliefs among financial analysts are indeed heterogeneous. These findings are able to explain the abnormal volume of trade around earnings announcements even when prices do not change. However, the heterogeneity of expectations might play a significant role in asset pricing. A large number of models have been proposed that incorporate this hypothesis. A few relevant references are Harris and Raviv (1993) and Hong and Stein (1999). Some papers have also suggested that the combination of differences in beliefs and short-sales constraints can explain persistent deviations of stock prices from intrinsic valuations. In the presence of short-sales constraints, investors that are pessimistic about a stock will not be able to short the stock and they will simply not hold it. However, optimistic agents will buy the stock and the market price will be such that it reflects only the optimistic valuations in the population. This hypothesis was introduced by Miller (1977) and is recently reconsidered by Chen et al. (2002) and Hong and Stein (2003). The empirical implications for the cross-section of stock returns is investigated by Diether et al. (2002).

In our model we assume that the fundamental value of the asset is common knowledge. However, investors have heterogeneous beliefs about the speed of reversion of stock prices towards the intrinsic valuation. They expect that a mispricing will adjust at different horizons. For example, assume the market is currently overvalued. In our setup, this is common knowledge but one group of agents, the fundamentalists, is pessimistic and believes that this situation will soon be corrected. However, the rest of the population, the trend followers, is optimistic and believes that in the short run the price trend will continue. Our model allows for the coexistence of groups with different sentiment about the evolution of the stock market. This assumption is supported by the survey evidence in Shiller (2000), Fisher and Statman (2002) and Vissing-Jorgensen (2003). These surveys involve both institutional and individual investors from different sources during the 90s. A common result emerges from them. During the surge in stock prices of the 90s, a large fraction of investors were aware of the overvaluation but they continued to buy stocks because they expected the mispricing to be corrected only at longer-horizons. Vissing-Jorgensen 
(2003) reports that at the beginning of $2000,50 \%$ of individual investors considered the stock market to be overvalued, approximately $25 \%$ believed that it was fairly valued and less than $10 \%$ that it was undervalued. This is a clear indication that opinions among individual investors were heterogeneous and that they had different beliefs about the prospect of the stock market. Similar survey evidence for exchange rate expectations has been found by Frankel and Froot $(1987,1990)$. Their survey data analysis shows that financial experts extrapolate past trends in exchange rates at short horizons from 1 week up to 3 months, whereas the same experts have mean reverting expectations at longer horizons of 6-12 months. They also provide evidence that from the end of the seventies until the mid eighties the relative proportion among forecasting services of trend-following beliefs compared to fundamental mean reverting rules, increased. They argue that the relative popularity of technical trading rules compared to fundamental rules may have amplified the strong rise of the dollar exchange rate in the early eighties and its subsequent fall after February 1985. Shiller (2000) finds similar evidence that the sentiment of investors varies significantly over time. Both for institutional and individual investors there is evidence that they become more optimistic (or more bullish) in response to significant increases in the recent performance of the stock market. This evidence supports one of the key assumption of our model: evolutionary switching between different beliefs or investment strategies. We assume that agents adopt a belief based on its past performance relative to the competing strategies. If a belief performs relatively well, as measured by realized profits, it attracts more investors. Instead, the fraction of the agents using the "losing" strategies will decrease. Realized returns thus contribute to give more support to some of the beliefs strategies rather than others and lead to time variation in the sentiment of the market. The assumption of evolutionary switching among beliefs adds a dynamical aspect that is missing in most of the models with heterogeneous opinions mentioned above. In our model investors are boundedly rational because they learn from the past performance of the strategies which one is more likely to be successful in the near future. They do not use in every period the same predictor and make mistakes, but switch between beliefs in order to minimize their errors. Our model is also consistent with asset market laboratory experiments such as Smith et al. (1988), who found bubbles and crashes in their asset market experiments. Recent asset pricing laboratory experiments in Hommes et al. (2005) show that agents may coordinate expectations on trend following behavior and mean reversion, leading to asset price fluctuations around a constant fundamental price.

Our paper is also related to earlier work on assessing the contributions of market fun- 
damentals and rational bubbles to stock-price fluctuations, for example in Blanchard and Watson (1982), Flood and Hodrick (1990), West (1987) and Diba and Grossman (1988). In our behavioral model agents are not fully rational, but at least boundedly rational in the sense that they are driven by short run profitability. In particular, the model of Evans (1991) of periodically collapsing rational bubbles is somewhat similar in spirit. In this model asset prices grow at a rate larger than the risk free rate for some time, but have an exogenously given positive probability of collapsing in each period. In our behavioral model asset prices also exhibit different phases of larger growth than the discount rate, when trend followers dominate the market, and mean reversion when fundamentalists dominate, with the probability of switching between the two phases determined endogenously by recent realized profits.

Our paper may be seen as one of the first attempts to estimate a behavioral model with heterogeneous agents on stock market data. Only few attempts have been made to estimate a heterogeneous agent model (HAM). An early example is Shiller (1984), who presents a heterogeneous agent model with smart money traders, having rational expectations, versus ordinary investors (whose behavior is in fact not modeled at all). Shiller estimates the fraction of smart money investors over the period 1900-1983, and finds considerable fluctuations of the fraction over a range between 0 and 50\%. More recently, Baak (1999) and Chavas (2000) estimate HAMs on hog and beef market data, and found evidence for the heterogeneity of expectations. For the beef market Chavas (2000) finds that about $47 \%$ of the beef producers behave naively (using only the last price in their forecast), $18 \%$ of the beef producers behaves rationally, whereas $35 \%$ behaves quasi-rationally (i.e. use a univariate autoregressive time series model of prices in forecasting). Winker and Gilli (2001) and Gilli and Winker (2003) estimate the exchange rate model of Kirman (1991, 1993) with fundamentalists and chartists, using the daily DM-US\$ exchange rates 1991-2000. Their estimated parameter values correspond to a bimodal distribution of agents, and Gilli and Winker (2003) conclude that the foreign exchange market can be better characterized by switching moods of the investors than by assuming that the mix of fundamentalists and chartists remains stable over time. Westerhoff and Reitz (2003) also estimate an HAM with fundamentalists and chartists to exchange rates and find considerable fluctuations of the market impact of fundamentalists. Another recent example is Alfarano et al. (2005) who estimate a simple agent-based financial market model with herding using returns from gold prices, stock prices of two large German companies and the DAX stock market index. Another empirical application of a HAM with switching 
between fundamentalists and chartists is de Grauwe and Grimaldi (2006), who explain the main stylized facts of exchange rates. All these papers suggest that heterogeneity is important in explaining the data, but much more work is needed to investigate the robustness of this empirical finding. Our paper may be seen as one of the first attempts to estimate a behavioral HAM on stock market data and investigate whether behavioral heterogeneity is significant.

\section{The Model}

We consider the asset pricing model with heterogeneous beliefs introduced by Brock and Hommes $(1997,1998)$ and reformulate the model in terms of price to cash flow in order to estimate the model on yearly S\&P 500 data. There are two assets available, a risky and a riskless asset. The riskless asset is in perfectly elastic supply and pays a constant return $r$. The risky asset is in zero net supply and pays an uncertain cash flow $Y_{t}$ in each period. The price of the risky asset in period $t$ is denoted by $P_{t}$. The excess return of the risky asset is defined as

$$
R_{t+1}=P_{t+1}+Y_{t+1}-(1+r) P_{t}
$$

We assume that investors have heterogeneous beliefs about future payoffs. In particular, we assume that agents choose among $H$ types of beliefs or forecasting rules. The expectation of investors type $h$ about the conditional mean and variance of the excess return are $E_{h, t}\left[R_{t+1}\right]$ and $V_{h, t}\left[R_{t+1}\right]$, for $h=1, \ldots, H$. We assume that type $h$ agents have a myopic mean-variance demand function with risk aversion parameter $a_{h}$, given by

$$
z_{h, t}=\frac{E_{h, t}\left[R_{t+1}\right]}{a_{h} V_{h, t}\left[R_{t+1}\right]}
$$

For analytical tractability, following Brock and Hommes (1998), we assume that all investors have the same risk aversion parameter, $a_{h}=a$, and that they have homogeneous expectations about the conditional variance, $V_{h, t}\left[R_{t+1}\right] \equiv V_{t}\left[R_{t+1}\right]$. The only source of heterogeneity that we allow in the model concerns the beliefs about the future payoffs of the risky asset. We denote the fraction of investors in the economy using predictor $h$ at time $t$ by $n_{h, t}$. Under the assumption of zero net supply of the risky asset, the market clearing equation is

$$
\sum_{h=1}^{H} n_{h, t} \frac{E_{h, t}\left[P_{t+1}+Y_{t+1}\right]-(1+r) P_{t}}{a V_{t}\left[R_{t+1}\right]}=0,
$$


and the equilibrium pricing equation is thus given by

$$
P_{t}=\frac{1}{1+r} \sum_{h=1}^{H} n_{h, t} E_{h, t}\left(P_{t+1}+Y_{t+1}\right) .
$$

According to (4) the price at time $t$ of the risky asset is given by the discounted, weighted average (by the fractions) of investors' beliefs about next period pay-offs. Notice that the equilibrium pricing equation (4) is equivalent to

$$
r=\sum_{h=1}^{H} n_{h, t} \frac{E_{h, t}\left[P_{t+1}+Y_{t+1}-P_{t}\right]}{P_{t}},
$$

that is, in equilibrium the average required rate of return for investors to hold the risky asset equals the discount rate $r$. In the estimation of the model in Section 4 the discount rate $r$ will be set equal to the sum of the (risk free) interest rate and the required risk premium on stocks ${ }^{1}$. From (4) it is clear that the equilibrium price will be high if an optimistic type dominates the market, that is, when the fraction of investors expecting a high next period payoff is large. On the other hand, pessimistic beliefs about future payoffs will drive the equilibrium price to lower levels. We assume that investors have homogeneous expectations about the cash flow. In contrast to Brock and Hommes (1998), who assume an IID process for the cash flow, we consider a non-stationary cash flow with a constant growth rate. More precisely, we assume that $\log Y_{t}$ is a Gaussian random walk with drift, that is,

$$
\log Y_{t+1}=\mu+\log Y_{t}+v_{t+1}, \quad v_{t+1} \sim \text { i.i.d. } N\left(0, \sigma_{v}^{2}\right)
$$

This implies

$$
\frac{Y_{t+1}}{Y_{t}}=e^{\mu+v_{t+1}}=e^{\mu+\frac{1}{2} \sigma_{v}^{2}} e^{v_{t+1}-\frac{1}{2} \sigma_{v}^{2}}=(1+g) \varepsilon_{t+1},
$$

where $g=e^{\mu+\frac{1}{2} \sigma_{v}^{2}}-1$ and $\varepsilon_{t+1}=e^{v_{t+1}+\frac{1}{2} \sigma_{v}^{2}}$, which implies $E_{t}\left(\varepsilon_{t+1}\right)=1$. We assume that all types have correct beliefs on the cash flow, that is,

$$
E_{h, t}\left[Y_{t+1}\right]=E_{t}\left[Y_{t+1}\right]=(1+g) Y_{t} E_{t}\left[\varepsilon_{t+1}\right]=(1+g) Y_{t}
$$

Since the cash flow is an exogenously given stochastic process it seems natural to assume that agents have learned the correct beliefs on next periods cash flow $Y_{t+1}$. In particular,

\footnotetext{
${ }^{1}$ Alternatively, the model can be extended to allow for a nonzero risk premium by introducing a positive net supply of the risky asset. This is not considered here for analytical tractability.
} 
boundedly rational agents can learn about the constant growth rate e.g. by running a simple regression of $\log \left(Y_{t} / Y_{t-1}\right)$ on a constant. In contrast, prices are determined endogenously and in particular prices are affected by expectations about next period's price. In a heterogeneous world, agreement about next period's price therefore seems more unlikely than agreement about the cash flow, and therefore we will assume heterogeneous beliefs about next period's price as discussed below. The pricing equation (4) can be reformulated in terms of price-to-cash-flow $(\mathrm{PY})$ ratio, $\delta_{t}=P_{t} / Y_{t}$, as

$$
\delta_{t}=\frac{1}{R^{*}}\left\{1+\sum_{h=1}^{H} n_{h, t} E_{h, t}\left[\delta_{t+1}\right]\right\}, \quad \quad R^{*}=\frac{1+r}{1+g} .
$$

where we assume that the dividend growth $Y_{t+1} / Y_{t}$ is conditionally independent of $\delta_{t+1}$, that is,

$$
E_{h, t}\left[\frac{P_{t+1}}{Y_{t}}\right]=E_{h, t}\left[\delta_{t+1}\right] E_{h, t}\left[\frac{Y_{t+1}}{Y_{t}}\right]=(1+g) E_{h, t}\left[\delta_{t+1}\right]
$$

In the special case, when all agents have rational expectations the equilibrium pricing equation (4) simplifies to

$$
P_{t}=\frac{1}{1+r} E_{t}\left(P_{t+1}+Y_{t+1}\right)
$$

It is well known that, in the case of a constant growth rate $g$ for dividends, the rational expectations fundamental price, $P_{t}^{*}$, of the risky asset is given by

$$
P_{t}^{*}=\frac{1+g}{r-g} Y_{t}, \quad r>g,
$$

or equivalently, in terms of price-to-cash flow ratios

$$
\delta_{t}^{*}=\frac{P_{t}^{*}}{Y_{t}}=\frac{1+g}{r-g} \equiv m
$$

We will refer to $P_{t}^{*}$ as the fundamental price and to $\delta_{t}^{*}$ as the fundamental PY-ratio. When all agents are rational the pricing equation (9) in terms of the PY-ratio, $\delta_{t}=P_{t} / Y_{t}$, becomes

$$
\delta_{t}=\frac{1}{R^{*}}\left\{1+E_{t}\left[\delta_{t+1}\right]\right\} .
$$

In terms of the deviation from the fundamental ratio, $x_{t}=\delta_{t}-\delta_{t}^{*}=\delta_{t}-m$, this simplifies to

$$
x_{t}=\frac{1}{R^{*}} E_{t}\left[x_{t+1}\right]
$$


Under heterogeneity in expectations, the pricing equation (9) is expressed in terms of $x_{t}$ as

$$
x_{t}=\frac{1}{R^{*}} \sum_{h=1}^{H} n_{h, t} E_{h, t}\left[x_{t+1}\right] .
$$

\section{Heterogeneous beliefs}

We now specify how agents form their beliefs about next period's PY-ratio. We assume that the fundamental PY-ratio is known to all investors. However, agents have different beliefs about the persistence of the deviation from the fundamental. The expectation of belief type $h$ about next period PY-ratio is expressed as

$$
E_{h, t}\left[\delta_{t+1}\right]=E_{t}\left[\delta_{t+1}^{*}\right]+f_{h}\left(x_{t-1}, \ldots, x_{t-L}\right)=m+f_{h}\left(x_{t-1}, \ldots, x_{t-L}\right),
$$

where $\delta_{t}^{*}$ represents the fundamental PY-ratio, $E_{t}\left(\delta_{t+1}^{*}\right)=m$ is the rational expectation of the PY-ratio available to all agents, $x_{t}$ is the deviation of the PY-ratio from its fundamental value and $f_{h}(\cdot)$ represents the expected transitory deviation of the PY-ratio from the fundamental value, depending on $L$ past deviations. The information available to investors at time $t$ includes present and past cash flows and past prices. In other words, we do not allow agents to react to the contemporaneous equilibrium price but only to past realized prices. This assumption about the information set available to traders was previously used by Hellwig (1982) and Blume et al. (1994) in a rational expectations setup. Another way of interpreting this assumption is that investors can only trade using market orders. A similar assumption is also used by Hong and Stein (1999). At the beginning of the period agents choose their optimal demand of the risky asset determined by past realized prices and at the end of period $t$, the market clearing price $P_{t}$ is determined. We can reformulate Equation (17) in terms of deviations from the fundamental PY-ratio, $x_{t}$, as

$$
E_{h, t}\left[x_{t+1}\right]=f_{h}\left(x_{t-1}, \ldots, x_{t-L}\right)
$$

The function $f(\cdot)$ can be interpreted as the belief of investors type $h$ about the evolution of the transitory component in the asset price. Note that the rational expectations, fundamental benchmark is nested in our heterogeneous agent model as a special case when $f_{h} \equiv 0$ for all types $h$. In Section 4 we will estimate the model to investigate whether deviations from the benchmark fundamental are significant. We can express Equation (16) 


$$
R^{*} x_{t}=\sum_{h=1}^{H} n_{h, t} f_{h}\left(x_{t-1}, \ldots, x_{t-L}\right) .
$$

From this equilibrium equation it is clear that the adjustment towards the fundamental PY-ratio will be slow if a majority of investors has persistent beliefs about it.

\section{Evolutionary selection of expectations}

In addition to the evidence of persistent deviations from the fundamentals there is also significant evidence of time variation in the sentiment of investors. This has been documented, for example, by Shiller (2000) using survey data. In the model considered here, agents are boundedly rational and switch between different forecasting strategies according to relative recently realized profits. At the beginning of period $t$ the realized profits for each of the strategies are publicly available. We denote by $\pi_{h, t-1}$ the realized profits of type $h$ at the end of period $t-1$, given by

$$
\pi_{h, t-1}=R_{t-1} z_{h, t-2}=R_{t-1} \frac{E_{h, t-2}\left[R_{t-1}\right]}{a V_{t-2}\left[R_{t-1}\right]}
$$

where $R_{t-1}=P_{t-1}+Y_{t-1}-(1+r) P_{t-2}$ is the realized excess return, as given in (1), at time $t-1$ and $z_{h, t-2}$ indicates the demand of the risky asset by belief type $h$, as given in (2), formed in period $t-2$. In other words, $\pi_{h, t-1}$ represents the excess profit realized in the previous period by strategy $h$, in terms of quantities observed at the beginning of period $t$. In order to have a convenient expression of the excess profit in terms of the PY-ratio, we make two more simplifying assumptions. The first assumption is to approximate realized excess return in (20) by

$$
\begin{aligned}
R_{t-1}=P_{t-1}+Y_{t-1}-(1+r) P_{t-2} & =\left(\delta_{t-1}+1\right) Y_{t-1}-(1+r) P_{t-2} \\
& \approx\left(\delta_{t-1}+1\right)(1+g) Y_{t-2}-(1+r) P_{t-2} \\
& =\left(\delta_{t-1}+1-R^{*} \delta_{t-2}\right)(1+g) Y_{t-2}
\end{aligned}
$$

where $R^{*}=(1+r) /(1+g)$ as before. The approximation involves replacing the stochastic dividend/earnings part $Y_{t-1}$ of realized excess return by average or expected cash flow $(1+g) Y_{t-2}$. Under this assumption, the fitness measure is not affected by the stochastic growth rate of the dividend, but rather depends on the average growth rate $g$. Brock and Hommes (1998) refer to the model where stochastic dividend is replaced by expected 
dividend as the nonlinear deterministic skeleton model. The implied expected return is

$$
E_{h, t-2}\left[R_{t-1}\right]=\left(E_{h, t-2}\left[\delta_{t-1}\right]+1-R^{*} \delta_{t-2}\right)(1+g) Y_{t-2} .
$$

A second simplifying assumption concerns the beliefs about the conditional variance of excess returns. Recall that we already assumed these beliefs to be the same for all types. In the special case of an IID cash flow $Y_{t}$, Brock and Hommes (1998) made the assumption that the beliefs about the conditional variance of excess returns are the same and constant for all types, i.e. $V_{h, t-2}\left[R_{t-1}\right]=V_{t-2}\left[R_{t-1}\right]=\sigma^{2}$. Note that this is equivalent to assuming that all types have fundamentalists' beliefs about conditional variance. We follow the same approach here in the case of a cash flow $Y_{t}$ with constant growth rate, so that for all types the beliefs about conditional variance is given by

$$
\begin{aligned}
V_{h, t-2}\left[R_{t-1}\right] & =V_{h, t-2}\left[P_{t-1}+Y_{t-1}-(1+r) P_{t-2}\right]=V_{t-2}\left[P_{t-1}^{*}+Y_{t-1}-(1+r) P_{t-2}^{*}\right] \\
& =V_{t-2}\left[(m+1) Y_{t-1}-(1+r) m Y_{t-2}\right]=V_{t-2}\left[(m+1)(1+g) Y_{t-2} \epsilon_{t-1}\right]=Y_{t-2}^{2} \eta^{2},
\end{aligned}
$$

where $\eta^{2}=(1+m)^{2}(1+g)^{2} V_{t-2}\left[\epsilon_{t-1}\right]$. Combining (20) with (21)-(23), the fitness measure can now be rewritten in terms of the PY-ratio $\delta_{t}$ as

$$
\begin{aligned}
\pi_{h, t-1} & =R_{t-1} \frac{E_{h, t-2}\left[R_{t-1}\right]}{a V_{t-2}\left[R_{t-1}\right]} \\
& =\left(\delta_{t-1}+1-R^{*} \delta_{t-2}\right)(1+g) Y_{t-2} \frac{\left(E_{h, t-2}\left[\delta_{t-1}\right]+1-R^{*} \delta_{t-2}\right)(1+g) Y_{t-2}}{a Y_{t-2}^{2} \eta^{2}} \\
& =\frac{(1+g)^{2}}{a \eta^{2}}\left(\delta_{t-1}+1-R^{*} \delta_{t-2}\right)\left(E_{h, t-2}\left[\delta_{t-1}\right]+1-R^{*} \delta_{t-2}\right) .
\end{aligned}
$$

Using the deviation $x_{t}=\delta_{t}-m$ of the PY ratio from its fundamental value, with $m=$ $(1+g) /(r-g)$, we can further rewrite Equation (24) as

$$
\pi_{h, t-1}=\frac{(1+g)^{2}}{a \eta^{2}}\left(x_{t-1}-R^{*} x_{t-2}\right)\left(E_{h, t-2}\left[x_{t-1}\right]-R^{*} x_{t-2}\right) .
$$

This fitness measure has a simple, intuitive explanation in terms of forecasting performance for next period's deviation from the fundamental. A positive demand $z_{h, t-2}$ may be seen as a bet that $x_{t-1}$ would go up more than what was expected on average from $R^{*} x_{t-2}$. The realized fitness $\pi_{h, t-1}$ of strategy $h$ is the realized profit from that bet and it will be positive if both the realized deviation $x_{t-1}>R^{*} x_{t-2}$ and the forecast of the deviation $E_{h, t-2}\left[x_{t-1}\right]>R^{*} x_{t-2}$. More generally, if both the realized absolute deviation $\left|x_{t-1}\right|$ and the absolute predicted deviation $\left|E_{h, t-2}\left[x_{t-1}\right]\right|$ to the fundamental value are larger than 
$R^{*}$ times the absolute deviation $\left|x_{t-2}\right|$, then strategy $h$ generates positive realized fitness. In contrast, a strategy that wrongly predicts whether the asset price mean reverts back towards the fundamental value or moves away from the fundamental generates a negative realized fitness.

At the beginning of period $t$ investors compare the realized relative performances of the different strategies and withdraw capital from those that performed poorly and move it to better strategies. The model assumes that the fractions $n_{h, t}$ evolve according to a discrete choice model with multinomial logit probabilities, that is

$$
n_{h, t}=\frac{\exp \left[\beta \pi_{h, t-1}\right]}{\sum_{k=1}^{H} \exp \left[\beta \pi_{k, t-1}\right]}=\frac{1}{1+\sum_{k \neq h} \exp \left[-\beta \Delta \pi_{t-1}^{h, k}\right]},
$$

where the parameter $\beta>0$ is called the intensity of choice and $\Delta \pi_{t-1}^{h, k}=\pi_{h, t-1}-\pi_{k, t-1}$ denotes the difference in realized profits of belief type $h$ compared to type $k$. Brock and Hommes $(1997,1998)$ proposed this model for endogenous selection of expectations rules. Anderson et al. (1993) contains an extensive discussion and many other economic applications of the multinomial logit model for describing the choice probabilities of boundedly rational agents among finitely many alternatives. The key feature of Equation (26) is that strategies with higher fitness (realized profits) in the recent past attract more followers. Stated differently, the evolutionary mechanism in (26) captures the performance based selection of the winning beliefs in the recent past. Agents are boundedly rational in the sense that they abandon beliefs that performed poorly in the recent past. Hence, they do not systematically make mistakes but learn about the most profitable predictor in the recent past. The intensity of choice parameter $\beta$ regulates the speed of transition between different beliefs. A high value of $\beta$ represents a situation in which agents react quickly to the most recent performances of the strategies. In this case they switch rapidly to last period's best performing belief. In contrast, a small value of $\beta$ corresponds to the case where agents are reluctant to switch to other beliefs unless they observe large performance differentials between the strategies.

\section{A simple two-type example}

Brock and Hommes (1998) studied the deterministic skeleton of the dynamic asset pricing model of Equations (19), (20) and (26) with various heterogeneous belief types, such as fundamentalists versus trend followers. They showed that the nonlinear evolutionary model may lead to multiple steady states, limit cycles and even chaotic asset price fluctu- 
ations around an unstable fundamental price. In the present application, we assume that the economy is characterized by two types of traders, that is $H=2$. We assume that both predict next period's deviation by extrapolating past realizations in a linear fashion, that is

$$
E_{h, t}\left[x_{t+1}\right]=f_{h}\left(x_{t-1}\right)=\phi_{h} x_{t-1} .
$$

In the estimation of the model in the next section, it turns out that higher order lags are not significant, so we focus on the simplest case with only one lag in the function $f_{h}(\cdot)$, with $\phi_{h}$ the parameter characterizing the strategy of type $h$. The dynamic asset pricing model can then be written as

$$
R^{*} x_{t}=n_{t} \phi_{1} x_{t-1}+\left(1-n_{t}\right) \phi_{2} x_{t-1}+\epsilon_{t},
$$

where $\phi_{1}$ and $\phi_{2}$ denote the coefficients of the two types of beliefs, $n_{t}$ represents the fraction of investors that belong to the first type of traders and $\epsilon_{t}$ represents a disturbance term. The value of the parameter $\phi_{h}$ can be interpreted as follows. If it is positive and smaller than 1 it suggests that investors expect the stock price to mean revert towards the fundamental value. We will refer to this type of agents as fundamentalists, because they expect the asset price to move back towards its fundamental value. The closer $\phi_{h}$ is to 1 the more persistent are the expected deviations. If the beliefs parameter $\phi_{h}$ is larger than 1 , it implies that investors believe the deviation of the stock prices to grow over time at a constant speed. We will refer to this type of agents as trend followers. Note in particular that when one group of investors believes in a strong trend, i.e. $\phi_{h}>R^{*}$, this may cause asset prices to deviate further from their fundamental value.

In the case with 2 types with linear beliefs with one lag, the fraction of type 1 investors is

$$
n_{t}=\frac{1}{1+\exp \left\{-\beta^{*}\left[\left(\phi_{1}-\phi_{2}\right) x_{t-3}\left(x_{t-1}-R^{*} x_{t-2}\right)\right]\right\}}
$$

where $\beta^{*}=\beta(1+g)^{2} /\left(a \eta^{2}\right)$. The fraction depends on the difference in extrapolation rates of the 2 groups, the deviation from the fundamentals and the last period change in deviations. Notice that in periods when the deviation is approximately constant, that is, $x_{t-1} \approx x_{t-2} \approx x_{t-3} \approx \bar{x}$, the fraction depends on the squared value of the deviation. If $\phi_{1}<\phi_{2}$, the fraction is close to 0.5 for small deviations while it tends to 1 for large $\bar{x}$. This suggests that when the first group has less persistent beliefs compared to the other group and deviations become large, their fraction increases towards 1 . Hence, there is evidence that the more stabilizing expectations become active when they are most needed, that is, 
when the asset price is far away from the fundamentals.

\section{Estimation Results}

In this section we estimate the two-type model in equations (28) and (29). We use an updated version of the data set described in Shiller (1989), consisting of annual observations of the S\&P500 index from 1871 to 2003 . We estimate the model with both dividends and earnings as cash flows. The valuation ratios are then the Price-to-Dividends (PD) and the Price-to-Earnings (PE) ratios.

A convenient feature of the model is that it has been formulated in deviations from a benchmark fundamental. After a choice for the fundamental price has been made, the model can be estimated. As discussed already in the previous section, we define the asset fundamental value using the static Gordon growth model (Gordon (1962)), that is, the Present Value Model (PVM) with constant discount rate $r$ and constant growth rate $g$ of the cash flow $Y_{t}$, for which

$$
P_{t}^{*}=m Y_{t}, \quad m=\frac{1+g}{r-g},
$$

where $P_{t}^{*}$ indicates the fundamental price of the asset. Under the assumptions of the static Gordon model the fundamental value of the asset is a multiple $m$ of its cash flow where $m$ depends on the discount rate $r$ and the cash flow growth rate $g$. The multiple $m$ can also be interpreted as the PD and PE ratios implied by the PVM model. In order to check the robustness of our estimation results, in Appendix B we also consider a dynamic version of the Gordon model proposed by Poterba and Summers (1988). In this case, we relax the assumption of a constant cash flow growth rate and allow for time variation in the fundamental value.

Recall also from the previous section that $R^{*}$ in $(28)$ is given by

$$
R^{*}=\frac{1+r}{1+g}
$$

where $g$ is the constant growth rate of the cash flow as before and the discount rate $r$ is the risk free interest rate plus a risk premium. We use an estimate of the risk premium -the difference between the expected return on the market portfolio of common stocks and the risk-free interest rate- to obtain $R^{*}$. Recently, Fama and French (2002) used the Gordon constant growth valuation model to measure the magnitude of the equity premium on 
the same dataset used in this paper. The return on stocks may be written as the rate of capital gain plus the cash-flow-yield $Y_{t} / P_{t-1}$, i.e.

$$
\frac{P_{t}+Y_{t}-P_{t-1}}{P_{t-1}}=\frac{P_{t}-P_{t-1}}{P_{t-1}}+\frac{Y_{t}}{P_{t-1}} .
$$

Under the Gordon model with constant growth rate $g$ of the cash flow, the rate of capital gain equals the growth rate of the cash flow. As in Fama and French (2002) we thus estimate the risk premium $R P$ by

$$
R P=g+y / p-i,
$$

where $y / p$ denotes the average dividend yield $Y_{t} / P_{t-1}$ and $i$ is the risk free interest rate. For annual data from 1871 to 2003 of the S\&P500 index the results are summarized in Table $1^{2}$.

\section{Table 1 about here}

Using dividends as a measure of cash flow, Fama and French (2002) found that the estimated equity premium has significantly decreased after 1951. We follow the same practice and find an estimate of the risk premium of 4.84\% in the period 1871-1950 and an estimate of $2.16 \%$ for 1951-2003. Our results slightly differ from theirs due to the longer sample that we consider. Fama and French (2002) do not find evidence of predictability of the dividend growth rate thus supporting the hypothesis that it does not vary over time. The last column of Table (1) reports the corresponding average price-dividend ratios. Before 1951 the PD-ratio is 18.6 and after 1951 it increases to 29.6, as illustrated in Figure 1 which also plots the corresponding fundamental value $P_{t}^{*}=m Y_{t}$. In the Introduction we outlined some of the explanations based on economic fundamentals for the decrease in the estimated equity premium. One possible explanation is the steady decline in the number of companies that pay-out dividends, as documented in Fama and French (2001). Such changes in dividend policies and share repurchases from companies might create transitory shifts in the mean of the PD ratio although the mean reversion pattern should not be affected.

We also use earnings as a measure of cash flow to check the robustness of our results. Fama and French (2002) use the earnings data only for the period 1951 until 2000 because of concerns about the quality of the data before 1950. When earnings are used to determine

\footnotetext{
${ }^{2}$ Our estimates are slightly different from Fama and French (2002), because as in Shiller (1989), we use the CPI index to deflate nominal values.
} 
the fundamental valuation we follow the practice of Campbell and Shiller (2001) and smooth earnings by a 10 years moving average. We do not find evidence of a significant change pre/post 1950 for the equity premium when earnings are considered. The estimated equity premium on the full sample is equal to $6.56 \%$. The corresponding average priceearnings ratio is 13.4, as illustrated in Figure 1.

Figure 1 suggests that there is a clear long-term co-movement of the stock price and the fundamental value. However, the PD and PE ratios take persistent swings away from the value predicted by the PVM model. This suggests that the fundamental value does not account completely for the dynamics of stock prices, as was suggested in the early debate on mean reversion by Summers (1986). A survey of the on-going debate is given in Campbell and Shiller (2001). Here we use the simple constant growth Gordon model for the fundamental price and estimate our two type model on deviations from this benchmark.

\section{Figure 1 about here}

Using yearly data of the S\&P 500 index from 1871 to 2003, we estimate the parameters $\left(\phi_{1}^{\prime}, \phi_{2}^{\prime}, \beta^{*}\right)$ in model (28) and (29) by NonLinear Least Squares (NLLS). Here, $\left(\phi_{1}^{\prime}, \phi_{2}^{\prime}\right)$ are parameter vectors of the linear forecasting rules of the two types, but for both types only the first lag turns out to be significant. Table (1) reports that the corresponding values of $R^{*}=(1+r) /(1+g)$ are 1.074 for the PE ratio, 1.055 for the PD ratio before 1950 and 1.034 after 1951. We report the $R^{2}$ of the regression, the value of the Akaike selection criterion (AIC), and the AIC for a linear AR(1) model, the estimated coefficient of the $\operatorname{AR}(1)$ model, the p-value of the Ljung-Box test, $Q_{L B}$, for residuals autocorrelation of $4^{\text {th }}$ order and the test statistic and p-value of the bootstrap F-test for linearity described in Appendix A. The standard errors are reported in parenthesis.

PD ratio: 1871-2003 The partial autocorrelation function (PACF) of the time series suggests only positive autocorrelation up to the first lag. This is also confirmed by the estimation results for the model with one lag in the forecasting rules which do not show signs of misspecification of the model. The estimation results are as follows:

$$
\begin{gathered}
R^{*} x_{t}=n_{t}\left\{0.762 x_{t-1}\right\}+\left(1-n_{t}\right)\left\{1.135 x_{t-1}\right\}+\widehat{\epsilon}_{t} \\
n_{t}=\left\{1+\exp \left[-10.29\left(-0.373 x_{t-3}\right)\left(x_{t-1}-R^{*} x_{t-2}\right)\right]\right\}^{-1}
\end{gathered}
$$


$R^{2}=0.82, A I C=3.17, A I C_{A R(1)}=3.31, \phi_{A R(1)}=0.968, Q_{L B}(4)=0.44, F^{b o o t}(p$-value $)=22.04(0.00)$

The belief coefficients are strongly significant and different from each other. On the other hand, the intensity of choice $\beta^{*}$ is not significantly different from zero. We emphasize however, that it is a common result in switching-type regression models that the parameter $\beta^{*}$ in the transition function is hardly significant and has a large standard deviation, because large changes in $\beta^{*}$ cause only small variation of the fraction $n_{t}$. As suggested by Teräsvirta (1994), this should not be worrying as long as there is significant heterogeneity in the estimated regimes. The nonlinear switching model achieves a lower value for the AIC selection criterion compared to a linear AR(1) model. This suggests that the model is capturing nonlinearity in the data. This is also confirmed by the bootstrap F-test for linearity that strongly rejects the null hypothesis of linearity in favor of the heterogeneous agent model. The residuals of the regression do not show significant evidence of autocorrelation at the $5 \%$ significance level.

The estimated coefficient of the first regime is 0.76 , corresponding to an half-life of about two and a half years. The first regime can be characterized as fundamentalist beliefs, expecting the asset price to move back towards its fundamental value. In contrast, the second regime has an estimated coefficient equal to 1.13, implying that in this regime agents are trend followers, believing the deviation of the stock price to grow over time at a constant speed larger than $R^{*}$. When the fraction of investors using this belief is equal or close to 1 we have an explosive behavior in the PD ratio. We can represent the sentiment of investors as switching between a stable fundamentalists regime and a trend following regime. In normal periods agents consider the deviation as a temporary phenomenon and expect it to revert back to fundamentals quickly. In other periods, a rapid increase of stock prices not paralleled by improvements in the fundamentals causes losses for fundamentalists and profits for trend followers. Evolutionary pressure will then cause more fundamentalists to become trend followers, thus reenforcing the trend in prices.

\section{Figure 2 about here}

Figure 2 shows the time series of the fraction of fundamentalists, a scatter plot of the fraction of fundamentalists against the difference in profits of the two strategies and the time series of the average market sentiment at date $t$, defined as

$$
\phi_{t}=\frac{n_{t} \phi_{1}+\left(1-n_{t}\right) \phi_{2}}{R^{*}}
$$


It is clear that the fraction of fundamentalists varies considerably over time with periods in which it is close to 0.5 and other periods in which it is close to either of the extremes 0 or 1. The series of the average market sentiment shows that there is significant time variation between periods of strong mean reversion when the market is dominated by fundamentalist and other periods in which $\phi_{t}$ is close to or exceeds 1 and the market is dominated by trend followers. These plots also offer an explanation of the events of the late 90s: for four consecutive years the trend following strategy outperformed the fundamentalists strategy and a majority of agents switched to the trend following strategy, driving the average market sentiment beyond 1 thus reenforcing the strong price trend. However, at the turn of the market in 2000 the fraction of fundamentalists increased again, approaching 1 thus contributing to the reversal toward the fundamental value in subsequent years.

PE ratio: 1881-2003 Also for the deviations from the PE ratio the best model specification includes only one lag for the forecasting rules. The estimation results are as follows:

$$
\begin{gathered}
R^{*} x_{t}=n_{t}\left\{0.80 x_{t-1}\right\}+\left(1-n_{t}\right)\left\{1.097 x_{t-1}\right\}+\widehat{\epsilon}_{t} \\
n_{t}=\left\{1+\exp \left[-7.54\left(-0.29 x_{t-3}\right)\left(x_{t-1}-R^{*} x_{t-2}\right)\right]\right\}^{-1}
\end{gathered}
$$

$$
R^{2}=0.77, A I C=2.23, A I C_{A R(1)}=2.29, \quad \phi_{A R(1)}=0.983, Q_{L B}(4)=0.94, F^{\text {boot }}(p \text {-value })=10.15 \quad(0.011)
$$

The belief parameters are strongly significant but the intensity of choice, $\beta^{*}$, is not significantly different from zero. As before, the estimation results show that there are two significantly different regimes: one characterized by a coefficient 0.80 and the other by a coefficient equal to 1.097. The estimated parameters are close to the estimated values for the $\mathrm{PD}$ ratio. The qualitative interpretation of the regimes is the same as before: one group of fundamentalists believing that the stock price will mean revert towards the fundamental value and another group of trend followers believing that prices will persistently deviate from the fundamental valuation.

\section{Figure 3 about here}

Figure 3 shows the time series plot of the fraction of fundamentalists. The pattern of the fluctuations in the fraction, between the extremes 0 and 1 is similar to the PD ratio. In particular, the dynamics of fractions during the late 90 s is similar for both the PD 
and $\mathrm{PE}$ ratio: in 1995 the fraction of fundamentalists was close to zero and almost all agents extrapolated aggressively using the trend following belief; this situation persisted until 2000 when the stock market turned direction and the fraction of fundamentalists jumped close to 1 and almost all agents believed that it was time for stock prices to revert back towards the fundamental values. The fraction of fundamentalists remained close to 1 in the following years absorbing quickly the deviation from the fundamentals. Also the average market sentiment suggests a similar interpretation: historically there have been years in which the market was dominated by trend followers. In particular, in the late $90 \mathrm{~s}$ the average market sentiment $\phi_{t}$ was larger than 1 for a number of years, driving stock prices further away from their fundamental valuation.

The estimation results suggest that we identify two different belief strategies: one in which agents expect continuation of returns and the other in which they expect reversal. We also find that there are some years in which one type of expectations dominates the market. Our results indicate that in most periods the population of investors is divided in groups adopting different strategies. The persistence of the continuation regime is clearly influenced by the annual frequency of the data that we are using. Probably, using quarterly or monthly observations would indicate more persistence in the trend regime. However, it is clear that the expectation of continuation of positive returns dominated the market in the late 90s. Both for the PD and PE ratios the market sentiment coefficient $\phi_{t}$ (defined in Equation (35)) is larger than 1 in the late 90s. Despite the awareness of the mispricing, in this period investors were aggressively extrapolating the continuation of the extraordinary performances realized in the past years. Our empirical findings support the assumptions of BSV. Although there are marked differences with our model, they provide a similar explanation for the mechanism of continuation and reversal. Investors switch between expecting earnings to follow a trend or a mean reverting process. This implies that prices will also have a trend or revert back to the true (random walk) fundamentals. However, BSV assume that at each period the entire population either believes in continuation or reversal. Instead, our model accounts for the fact that the average market sentiment results from a group of investors expecting continuation and another group expecting mean reversion toward the fundamental. Another advantage of our approach is that we endogenize the switching of agents among beliefs. The evolutionary mechanism that relates predictor choice to their past performance is supported by the data. It confirms also previous evidence that pointed in this direction. Based on answers to a survey, Shiller (2000) constructed indices of "Bubble Expectations" and of "Investor Confidence". In 
both cases, he finds that the time variation in the indices is well explained by the lagged change in stock prices. Based on a different survey, Fisher and Statman (2002) find that in the late 90s individual investors had expectations of continuation of recent stock returns while institutional investors were expecting reversals. This is an interesting approach to identify heterogeneity of beliefs based on the type of investors rather than the type of beliefs.

\section{$5 \quad$ Empirical Implications}

In this section we discuss empirical implications of the estimation of our nonlinear evolutionary switching model with heterogeneous beliefs. First, we investigate the response to a positive shock to fundamentals when the asset is overvalued. Secondly, we address the question concerning the probability that a bubble may resume by considering the evolution of the valuation ratios conditional on being at the end of 2003. These simulation experiments are related and both show the importance of considering nonlinear effects in the dynamics of stock prices.

\subsection{Response to a Fundamental Shock}

We use the estimated parameters to investigate the response of the market valuation to good news. Assume that at the beginning of period $t$ the cash flow increases due to a permanent increase in the growth rate. This implies that the asset has a higher fundamental valuation ratio, but what is the effect on the market valuation? We address this question both for the linear and the nonlinear switching model. The linear model may be interpreted as a representative agent model believing in an average mean reversion towards the fundamental. We only consider the estimated parameter values for the PDratio; the results for the $\mathrm{PE}$-ratio are similar. Assume that at $t-1$ the fundamental valuation ratio was 15 and the good news at time $t$ drives it to 17 . Assume also that the equilibrium price at $t-1$ was 16 . Figure 4 shows the valuation ratio dynamics in response to the good news for both the linear and the heterogeneous agent models.

\section{Figure 4 about here}

The Figure shows the average price path over 2000 simulations of the estimated model in eq. (34). There is a clear difference between the linear and the nonlinear model. In the linear case, the positive shock to the fundamental value leads to an immediate increase of 
the price followed by a mean-reversion thereafter. In contrast, for the nonlinear heterogeneous agent model, the pattern that emerges is consistent with the evidence of short-run continuation of positive returns and long-term reversal. After good news, the agents incorporate the news into their expectations and they also expect that part of the previous period overvaluation will persist this period. One group -the trend followers- overreacts and expects a further increase of the price, while the other group -the fundamentalistsexpects the price to diminish over time. The equilibrium price at time $t$ overshoots and almost reaches 18. However, in the following two periods trend followers continue to buy the stock and drive the price (and valuation ratio) even higher. Finally, the reversal starts and drives the ratio back to its long run fundamental value. Initially, the aggressive investors interpret the positive news as a confirmation that the stock overvaluation was justified by forthcoming news. However, the lack of further good news convinces most investors to switch to the mean reverting expectations and the stock price is driven back towards the fundamental.

\subsection{Will the bubble resume?}

We simulate the evolution of the valuation ratios using the proposed heterogeneous agent model, with the parameter values estimated in the previous section. We will then obtain the predicted evolution of the ratio conditional on the value realized at the end of 2003 . We generate innovations by reshuffling the estimated residuals and use them as innovations. Instead of focusing our attention only on the mean or the median of the distribution we consider the quantiles corresponding to $10,30,50,70$ and $90 \%$ probability over the 2000 replications of the estimated model in eq. (34) for the PD ratio and the estimated model in eq. (36) for the PE ratio. In addition to the quantiles predicted by our nonlinear model we also plot those predicted by a linear mean reverting model for the valuation ratios.

Figure 5 and 6 show the 1 to 5 periods ahead quantiles of the predictive distribution for the model when the parameters are set to the values estimated on the PD and PE ratio, respectively.

\section{Figure 5 about here}

\section{Figure 6 about here}

The linear model (right plot) predicts that the valuation ratio reverts back toward the mean at all the quantiles considered. In contrast, the behavioral model predicts that there is a significant probability that the ratio may increase again as a result of the activation 
of the trend following regime. The $70 \%$ and $90 \%$ quantiles clearly show that the PD-ratio may increase again to levels above 75 . Stated differently, our heterogeneous agent model predicts that with probability over $30 \%$ the PD-ratio may increase to more than 75 . Note however that the median predicts that the ratio should decrease as implied by the linear mean reverting model. Another implication of our model is that if the first (mean reverting) regime dominates the beliefs of investors, it will enforce a much faster adjustment than predicted by the linear model. This is clear from the bottom quantiles of the distributions. The results for the PE-ratio are similar, although somewhat less extreme. Our heterogeneous agent model with evolutionary switching predicts that with a probability of $15 \%$ the PE-ratio may increase towards values of almost 35 . These simulations show that predictions from a linear, representative agent model versus a nonlinear, heterogeneous agent model are quite different. In particular, extreme events with large deviations from the benchmark fundamental valuation are much more likely in a nonlinear world.

\section{Conclusion}

We have proposed a behavioral asset pricing model with endogenous evolutionary switching of investors between different forecasting strategies according to their relative past performances and estimate the model on yearly S\&P500 data from 1871-2003. Our estimation results show statistically significant behavioral heterogeneity and substantial time variation in the average sentiment of investors. Investors believe that fundamentals are driving the long term dynamics of stock prices, but they interpret the persistence of the deviation of stock prices from their benchmark fundamentals in a different way. If a recent increase in stock prices is observed, agents tend to extrapolate that the mispricing will increase even further and allocate more capital to the trend following belief. However, in periods of gradual price changes they believe that the deviation is transitory and will revert back to its historical mean. This type of time variability of agents average sentiment is also supported by the survey evidence in Shiller (2000).

In particular, our model suggests an evolutionary explanation of the "irrational exuberance" of stock prices in the late nineties. Starting in 1996 the behavior of stock prices was at odds with the evidence that when deviations are large they tend to revert back to their long run mean. From 1996 until 1999 the PD ratio indicated that the stock market was overvalued and it was likely to correct back to the fundamentals. The PE ratio gave the same indication, although less clearly and somewhat later in time. Despite the common feeling among investors that stocks were overvalued, the market continued to grow 
by approximately $30 \%$ a year. The estimation of our model shows that a large majority of investors had explosive, trend following beliefs about the persistence of the deviations from the fundamentals. Apparently, investors neglected the role of fundamental news and continued to buy stocks for purely speculative reasons. The extraordinary performance of the trend following strategy convinced most investors to adopt this type of beliefs. The outcome of our model is consistent with the view that fundamentalists with mean reverting expectations had limited capital to arbitrage the mispricing away and force stock prices back to the fundamental values. Our behavioral model suggests that in the mid nineties optimistic, boundedly rational investors, motivated by short run profitability, reinforced the rise in stock prices triggered by higher expected cash flows of the internet sector.

An important topic for future research is to investigate the robustness of behavioral heterogeneity in financial market data. In particular, we have chosen a very simple fundamental process, the static Gordon growth model with constant growth rate of dividends or earnings and constant discount rate, allowing only for one jump in the estimated risk premium based on dividends in 1950, as in Fama and French (2002). For deviations of this simple benchmark our estimation results show significant behavioral heterogeneity of fundamentalists and trend following trading strategies, both for fundamental valuation based on dividends and earnings. As a first step, we show in the Appendix that our estimation results are fairly robust, by considering deviations from a benchmark fundamental with time variation in the cash flow growth rate. With more time variation in the benchmark fundamental, the estimation results are similar and behavioral heterogeneity is significant. An important topic for future work is to investigate whether similar results can be found at higher frequencies, e.g. for quarterly, monthly weekly or daily stock market data.

Let us finally discuss some other recent related work linking nonlinear econometric models to a speculative model of asset prices $^{3}$. van Norden and Schaller (1999) study a time series switching model with two regimes, an explosive bubble regime and a collapsing bubble regime. The probability of being in the explosive regime depends negatively on the relative absolute deviation of the bubble from the fundamental. Stated differently, the larger the absolute relative deviation from the fundamental, the larger the probability that the (positive or negative) bubble collapses. Brooks and Katsaris (2005) extend this model to three regimes, adding a third dormant bubble regime where the bubble grows at the required rate of return without explosive expectations. Another novel feature of their extension is the observation that an abnormal trading volume is a signal of changing market

\footnotetext{
${ }^{3}$ We thank a referee for pointing out the related recent papers of Brooks and Katsaris (2005) and of van Norden and Schaller (1999)
} 
expectations about the future of a speculative bubble. In their model the probability that the bubble collapses increases when trading volume becomes abnormally high. This could be related to the empirical evidence provided by Kandel and Pearson (1995) who find a significant relation between heterogeneity of analysts expectations and abnormal trading volume.

These speculative models are somewhat different in spirit and do not start off, at least not explicitly, from micro foundations with heterogeneous agents and evolutionary selection of behavioral rules according to past recent performance. But these nonlinear switching models can be reconciled with our heterogeneous agent model and the framework of Brock and Hommes (1997, 1998), by modifying the evolutionary fitness measure and include absolute relative deviations from the fundamental price and trading volume in the fitness measure for strategy selection. A large absolute deviation from the fundamental would then act as a far from equilibrium stabilizing force, while abnormally high trading volume would act as a trigger event for bubble collapse. A distinctive feature of our approach is that investors' behavior is driven by short run profits. This may be particularly important for getting bubbles started. After a few positive random shocks to fundamentals, motivated by short run profits trend followers may reinforce the price rise and contribute to the start of a bubble. Another important difference concerns the probability of extreme, long lasting bubbles as in the late nineties. When investors' expectations are mainly based upon relative deviations from fundamentals a long lasting bubble becomes more and more likely to burst. In contrast, as long as investment strategies are to a large extent driven by short run profit opportunities such bubbles may continue for a long time and cause extreme deviations from fundamentals. Further empirical work on estimating various heterogeneous agent models and determining the main driving forces of large deviations from fundamentals is an important topic for future work. 


\section{Appendix A: Bootstrap F-test for Linearity}

We evaluate the statistical significance of the heterogeneous agent model compared to a linear model using a bootstrap approach. Standard testing procedures cannot be applied for this model because of the presence of a nuisance parameter. If we assume the null hypothesis that $\phi_{1}=\phi_{2}$ in Equation (28) then the intensity of choice $\beta$ in Equation (29) is not identified (under the null). On the other hand, if we assume the null that $\beta=0$, then the difference $\left(\phi_{1}-\phi_{2}\right)$ is not identified. To overcome this testing problem, we adapt the bootstrap approach proposed by Hansen (1996) to the case of the nonlinear model discussed in this paper. The test is carried out as follow:

1. Estimate the (unrestricted) nonlinear model in Equation (28)-(29) and the (restricted) linear model $R^{*} x_{t}=\gamma x_{t-1}+\eta_{t}$; calculate the $\mathrm{F}$ (or Wald) statistic given by $F=T\left(\hat{\sigma}_{\eta}^{2}-\hat{\sigma}_{\epsilon}^{2}\right) / \hat{\sigma}_{\epsilon}^{2}$ where $\hat{\sigma}_{\eta}^{2}$ denotes the residual variance (not degrees-of-freedom corrected) in the linear model and $\hat{\sigma}_{\epsilon}^{2}$ in the nonlinear model.

2. Simulate B series from the estimated linear model by resampling the fitted residuals $\hat{\eta}_{t}$

3. For each series calculate the bootstrap F statistic as described in step (1) and denote it $F_{b}^{*}(b=1, \ldots, B)$

4. The bootstrap p-value of the $\mathrm{F}$ statistic is given by $\sum_{b} I\left(F_{b}^{*}>F\right) / B$, where $I(\cdot)$ is the indicator function that is equal to 1 if the condition is satisfied.

\section{Appendix B: Time-Varying Fundamental Value}

\section{The dynamic Gordon model}

The standard approach to value an asset is to assume that it is equal to the present discounted value of the cash flows it generates, that is,

$$
P_{t}=E_{t}\left[\frac{1}{1+r_{t+1}}\left(P_{t+1}+Y_{t+1}\right)\right]
$$

where $P_{t}$ is the price of the asset at the end of period $t, Y_{t+1}$ is the cash flow paid during period $t+1$ and $r_{t+1}$ is the discount rate at time $t+1$. $E_{t}(\cdot)$ indicates the expectation conditional upon information available at time $t$. Solving Equation (37) forward for $T$ periods, applying the law of iterated expectations, and imposing the transversality condition we obtain

$$
P_{t}^{*}=E_{t}\left[\sum_{j=1}^{\infty}\left(\prod_{i=1}^{j} \frac{1}{1+r_{t+i}}\right) Y_{t+j}\right]
$$


where we indicate $P_{t}^{*}$ as the fundamental value. We define the growth rate of the cash flow process $g_{t}$ as $Y_{t+1}=\left(1+g_{t+1}\right) Y_{t}$, so that the fundamental value is given by

$$
P_{t}^{*}=E_{t}\left[\sum_{j=1}^{\infty}\left(\prod_{i=1}^{j} \frac{1+g_{t+i}}{1+r_{t+i}}\right) Y_{t}\right]
$$

The time variation of $g_{t}$ and $r_{t}$ and the nonlinearity in the pricing equation complicate the derivation of analytically tractable formulas. One approach to simplify the problem consists of assuming that the cash flow growth rate and the required rate of return are constant and equal to $g$ and $r$, respectively. Under these assumptions, Equation (39) implies the static Gordon model introduced in Equation (13), leading to,

$$
P_{t}^{*}=m Y_{t}
$$

where $m=(1+g) /(r-g)$. The stock price at time $t$ is given by the cash flow times a multiple that depends on the ex-ante required rate of return and the growth rate of cash flows. However, assuming the cash flow growth rate and the expected returns to be constant over time may be too restrictive. It is possible to allow for time variation by following the approach of Poterba and Summers (1988). They approximate the pricing formula given in (39) by a first-order Taylor expansion around the mean of the required return, $r$, and the mean of the growth rate, $g$,

$$
P_{t}^{*} \approx E_{t}\left[\sum_{j=1}^{\infty}\left(\frac{1+g}{1+r}\right)^{j}+\left.\frac{\partial P_{t}^{*}}{\partial r_{t+j}}\right|_{r}\left(r_{t+j}-r\right)+\left.\frac{\partial P_{t}^{*}}{\partial g_{t+j}}\right|_{g}\left(g_{t+j}-g\right)\right] Y_{t}
$$

where the partial derivatives are given by

$$
\begin{gathered}
\left.\frac{\partial P_{t}^{*}}{\partial r_{t+j}}\right|_{r}=-\frac{Y_{t}}{r-g} \alpha^{j}, \\
\left.\frac{\partial P_{t}^{*}}{\partial g_{t+j}}\right|_{g}=\frac{(1+r) Y_{t}}{(1+g)(r-g)} \alpha^{j},
\end{gathered}
$$

and $\alpha=(1+g) /(1+r)$. Substituting the derivatives into Equation (41), we get

$$
P_{t}^{*}=\left\{\frac{1+g}{r-g}-\frac{1}{(r-g)} E_{t}\left[\sum_{j=1}^{\infty} \alpha^{j}\left(r_{t+j}-r\right)\right]+\frac{1+r}{(1+g)(r-g)} E_{t}\left[\sum_{j=1}^{\infty} \alpha^{j}\left(g_{t+j}-g\right)\right]\right\} Y_{t} .
$$

The pricing formula depends on the expectations of investors about future ex-ante returns and cash flow growth rate. A typical assumption made in the literature is that the expectations follow an $\mathrm{AR}(1)$ process, that is

$$
E_{t}\left(r_{t+j}-r\right)=\rho^{j}\left(r_{t}-r\right)
$$




$$
E_{t}\left(g_{t+j}-g\right)=\phi^{j}\left(g_{t}-g\right)
$$

and the approximated pricing formula in Equation (44) becomes

$$
P_{t}^{*}=m_{t} D_{t}
$$

where $m_{t}$ is the time-varying multiplier given by

$$
m_{t}=\left\{\frac{1+g}{r-g}-\frac{\rho(1+g)}{(r-g)(1+r-\rho(1+g))}\left(r_{t}-r\right)+\frac{\phi(1+r)}{(r-g)(1+r-\phi(1+g))}\left(g_{t}-g\right)\right\} .
$$

This version of the fundamental value is known in the literature as the dynamic Gordon model because it defines asset prices as a time-varying multiplier of the cash flows. The multiplier in Equation (48) has a straightforward interpretation: if the required rate of return and the growth rate of cash flows are constant and equal to their mean then it collapses to the static multiplier of Equation (40). However, time variation in the required rate of return and/or in the cash flows growth rate changes the level of the multiplier. The response of fundamental prices to changes in $r_{t}$ and $g_{t}$ is similar to the case of the static Gordon: if investors require at time $t$ a return higher (lower) than the average $r$, this will decrease (increase) the multiplier and consequently prices. On the other hand, if cash flows grow at a higher (lower) rate at time $t$, this will increase (decrease) the multiplier and will affect positively (negatively) stock prices. Equation (48) shows that the multiplier depends also on the AR coefficients in the expectations of the required return and the cash flow growth rate. High $\rho$ and $\phi$ imply that shocks to $g_{t}$ and $r_{t}$ will have a persistent effect on the multiplier and on fundamental prices.

\section{Empirical Evidence}

We investigate the deviation of the stock price from the fundamental value defined by the dynamic Gordon model. In constructing the dynamic fundamental value we allow for time variation in the cash flow growth rate $g_{t}$ while we keep constant the discount rate $r$. For the PD ratio we consider one jump of the risk premium in 1950, as considered earlier, while it is constant over the full sample for the $\mathrm{PE}$ ratio. The $\mathrm{PD}$ and $\mathrm{PE}$ ratio resulting from the dynamic Gordon model Equation (48) are shown in Figure 7.

\section{Figure 7 about here}

The estimation results for the deviation of the stock price from the dynamic fundamental value based on dividends are reported below:

$$
\begin{gathered}
R^{*} x_{t}=n_{t}\left\{0.761 x_{t-1}\right\}+\left(1-n_{t}\right)\left\{1.14 x_{t-1}\right\}+\widehat{\epsilon}_{t} \\
n_{t}=\left\{1+\exp \left[-7.66\left(-0.379 x_{t-3}\right)\left(x_{t-1}-R^{*} x_{t-2}\right)\right]\right\}^{-1}
\end{gathered}
$$


$R^{2}=0.814, A I C=3.22, A I C_{A R(1)}=3.36, \quad \phi_{A R(1)}=0.891, Q_{L B}(4)=0.17, F^{b o o t}(p$-value $)=21.95(0.00)$

The results are similar to the static case given in Equation (34). This is due to the negligible difference between the static and the dynamic fundamental value, see the upper panel of Figure 7. The AR(1) coefficient for the dividend growth rate in Equation (46) is estimated at 0.01 before 1950 and 0.50 after 1950. Although the persistence of the growth rate has significantly increased after 1950, it is insufficient to explain the much higher persistence of the realized PD ratio. This is a point made earlier by Barsky and deLong (1993) that high persistence (they assume a unit root) in the dividend growth rate process is required in order to account for the dynamics of stock prices. However, historical data do not support the hypothesis of such high persistence in the cash flow process.

For the PE ratio the results for the dynamic Gordon model are qualitatively similar to the static case in Eq. (36), although the bootstrap F-test does not reject the null hypothesis of linearity at $5 \%$ significance level $(\mathrm{p}$-value $=0.056)$. The estimation results are

$$
\begin{gathered}
R^{*} x_{t}=n_{t}\left\{0.785 x_{t-1}\right\}+\left(1-n_{t}\right)\left\{1.103 x_{t-1}\right\}+\widehat{\epsilon}_{t} \\
n_{t}=\left\{1+\exp \left[-1.59\left(-0.318 x_{t-3}\right)\left(x_{t-1}-R^{*} x_{t-2}\right)\right]\right\}^{-1}
\end{gathered}
$$

$$
R^{2}=0.726, A I C=2.38, A I C_{A R(1)}=2.42, \quad \phi_{A R(1)}=0.948, Q_{L B}(4)=0.49, F^{b o o t}(p-\text { value })=6.69(0.056)
$$

Notice that for both the $\mathrm{PD}$ and $\mathrm{PE}$ ratio, the estimated coefficients of the trend following regime are very similar (1.14 versus 1.135 for the PD and 1.103 versus 1.097 for the PE ratio) for the dynamic Gordon compared to the static Gordon. This result is also supported by the F-test for linearity that rejects the null hypothesis at $10 \%$ for both ratio. This evidence suggests that our finding of behavioral heterogeneity seems fairly robust when time variation in the fundamental value is considered. 


\section{References}

Alfarano, S., Lux, T., Wagner, F., 2005. Estimation of agent-based models: the case of an asymmetric herding model. Computational Economics 26, 19-49.

Anderson, S., de Palma, A., Thisse, J., 1993. Discrete choice theory of product differentiation. MIT Press, Cambridge.

Baak, S.J., 1999. Tests for bounded rationality with a linear dynamic model distorted by heterogeneous expectations. Journal of Economic Dynamics and Control 23 , 1517-1543.

Barberis, N., Shleifer, A., Vishny, R. 1998.. A model of investor sentiment. Journal of Financial Economics 49, 307-343.

Barberis, N., Thaler, R. 2003. A survey of behavioral finance, in: Constantinides, G.M., Harris, M., Stulz, R. (Eds.), Handbook of the Economics of Finance, Elsevier.

Barsky, R.B., deLong, J.B., 1993. Why does the stock market fluctuate?. Quarterly Journal of Economics 58, 291-311.

Biais, B., Bossaerts, P., Spatt, C., 2003. Equilibrium asset pricing under heterogeneous information. mimeo.

Blanchard, O.J., Watson, M.W., 1982. Bubbles, rational expectations and financial markets, in: Wachtel, P. (Eds.), Crisis in the Economic and Financial System, Lexington Books, pp. 295-315.

Blume, L., Easley, D., O'Hara, M., 1994. Market statistics and technical analysis: The role of volume. Journal of Finance 49, 153-181.

Brock, W.A., Hommes, C.H., 1997. A rational route to randomness. Econometrica 65, 1059-1095.

Brock, W.A., Hommes, C.H., 1998. Heterogeneous beliefs and routes to chaos in a simple asset pricing model. Journal of Economic Dynamics and Control 22, 1235-1274.

Brooks, C., Katsaris, A., 2005. A three-regime model of speculative behaviour: Modelling the evolution of the S\&P500 Composite Index. Economic Journal 115, 767-797.

Campbell, J.Y., Shiller, R.J., 2001. Valuation ratios and the long-run stock market outlook: an update. NBER working paper 8221.

Chavas, J.P., 2000. On information and market dynamics: the case of the U.S. beef market. Journal of Economic Dynamics and Control, 24, 833-853.

Chen, J., Hong, H., Stein, J.C., 2002. Breadth of ownership and stock returns. Journal of Financial Economics 66, 171-205.

Cutler, D., Poterba, J., Summers, L., 1991. Speculative dynamics. Review of Economic Studies 58, 529-546.

Daniel, K., Hirshleifer, D., Subrahmanyam, A., 1998. Investor psychology and security market under- and overreactions. Journal of Finance 53, 1839-1885.

de Bondt, W., Thaler, R., 1985. Does the stock market overreact? Journal of Finance $42,557-581$. 
de Grauwe, P., Grimaldi, M., 2006. Exchange rate puzzles: a tale of switching attractors. European Economic Review 50, 1-33.

Diba, B.T., Grossman, H.I., 1988. Explosive rational bubbles in stock prices?. American Economic Review 78, 520-530.

Diether, K.B., Malloy, C.J., Scherbina, A., 2002. Differences of opinion and the cross section of stock returns. Journal of Finance 57(5), 2113-2141.

Evans, G.W., 1991. Pitfalls in testing for explosive bubbles in asset prices. American Economic Review81, 922-930.

Fama, E.F., French, K.R., 2001. (2001). Disappearing dividends: Changing firm characteristics or lower propensity to pay?. Journal of Financial Economics 60, 3-43.

Fama, E.F., French, K.R., 2002. The equity premium. Journal of Finance 57, 637-659.

Fisher, K.L., Statman, M., 2002. Blowing bubbles. Journal of Psychology and Financial Markets 3, 53-65.

Flood, R.P., Hodrick, R.J., 1990. On testing for speculative bubbles. Journal of Economic Perspectives 4, 85-101.

Frankel, J.A., Froot, K.A., 1987. Using survey data to test standard propositions regarding exchange rate expectations. American Economic Review 77, 133-153.

Frankel, J.A., Froot, K.A., 1990. Chartists, fundamentalists, and trading in the foreign exchange market. American Economic Review 80, 181-185.

Gilli, M., Winker, P., 2003. A global optimization heuristic for estimating agent based models. Computational Statistics \& Data Analysis 42, 299-312.

Gordon, M., 1962. The Investment Financing and Valuation of the Corporation. Irwin.

Grundy, B.D., Kim, Y., 2002. Stock market volatility in an heterogeneous information economy. Journal of Financial and Quantitative Analysis 37, 1-27.

Hansen, B., 1996. Inference when a nuisance parameter is not identified under the null hypothesis. Econometrica 64, 413-430.

Harris, M., Raviv, A., 1993. (1993). Differences of opinion make a horse race. Review of Financial Studies 6, 473-506.

Heaton, J., Lucas, D., 1999. Stock prices and fundamentals. NBER Macroeconomic Annual, 213-241.

Hellwig, M.F., 1982. Rational expectations equilibrium with conditioning on past prices: a mean-variance example. Journal of Economic Theory 26, 279-312.

Hirshleifer, D., 2001. Investor psychology and asset pricing. Journal of Finance 56, 15331597.

Hommes, C.H., 2006. Heterogeneous agent models in economics and finance, in: Judd, K.J., Tesfatsion, L. (Eds.), Handbook of Computational Economics, Vol. 2: AgentBased Computational Economics, North-Holland, in press.

Hommes, C.H., Sonnemans, J., Tuinstra, J., van de Velden, H., 2005. Coordination of expectations in asset pricing experiments. Review of Financial Studies 18, 955-980. 
Hong, H., Stein, J., 1999. A unified theory of underreaction, momentum trading and overreaction in asset markets. Journal of Finance 54, 2143-2184.

Hong, H., Stein, J.C., 2003. Differences of opinion, short-sales constraints, and market crashes. Review of Financial Studies 16(2), 487-525.

Jagannathan, R., McGrattan, E.R., Scherbina, A., 2000. The declining U.S. equity premium. Federal Reserve Bank of Minneapolis Quarterly Review 24, 3-19.

Jegadeesh, N., Titman, S., 1993. Returns to buying winners and selling losers: implications for stock market efficiency. Journal of Finance 48, 65-91.

Kandel, E., Pearson, N.D., 1995. Differential interpretation of public signals and trade in speculative markets. Journal of Political Economy 103, 831-872.

Kirman, A., 1991. Epidemics of opinion and speculative bubbles in financial markets, in: Taylor, M.P. (Eds.), Money and Financial Markets, MacMillan.

Kirman, A., 1993. Ants, rationality and recruitment. Quarterly Journal of Economics 108, 137-156.

LeRoy, S.F., Porter, R.D., 1981. The present-value relation: Tests based on implied variance bounds. Econometrica 49, 97-113.

Miller, E.M., 1977. Risk, uncertainty, and divergence of opinion. Journal of Finance 32, 1151-1168.

Ofek, E., Richardson, M., 2002. The valuation and market rationality of internet stock prices. Oxford Review of Economic Policy 18, 265-287.

Ofek, E., Richardson, M., 2003. Dotcom mania: The rise and fall of internet stock prices. Journal of Finance 53, 1113-1137.

Poterba, J.M., Summers, L.H., 1988. Mean reversion in stock prices: Evidence and implications. Journal of Financial Economics 22, 27-59.

Shiller, R.J., 1981. Do stock prices move too much to be justified by subsequent changes in dividends?. American Economic Review 71, 421-436.

Shiller, R.J., 1984. Stock prices and social dynamics. Brookings Papers in Economic Activity 2, 457-510.

Shiller, R.J., 1989. Market Volatility. MIT Press, Cambridge.

Shiller, R.J., 2000. Measuring bubble expectations and investor confidence. Journal of Psychology and Financial Markets 1, 49-60.

Smith, V., Suchanek, G.L., Williams, A.W., 1988. Bubbles, crashes and endogenous expectations in experimental spot asset markets. Econometrica 56, 1119-51.

Summers, L.H., 1986. Does the stock market rationally reflect fundamental values?. Journal of Finance 41, 591-602.

Teräsvirta, T., 1994. Specification, estimation, and evaluation of smooth transition autoregressive models. Journal of the American Statistical Association 89, 208-218.

van Norden, S. and Schaller, H., 1999. Speculative behavior, regime-switching, and stock market crashes, in: Rothman, P. (Eds.), Nonlinear Time Series Analysis of Economic and Financial Data, Kluwer, Dordrecht, pp. 321-356. 
Vissing-Jorgensen, A., 2003. Perspectives on behavioral finance: Does "irrationality" disappear with wealth? evidence from expectations and actions, in: Gertler, M., Rogoff, K. (Eds.), NBER Macroeconomics Annual, MIT Press.

West, K.D., 1987. A specification test for speculative bubbles. Quarterly Journal of Economics 102, 553-580.

Westerhoff, F.H., Reitz, S., 2003. Nonlinearities and cyclical behavior: the role of chartists and fundamentalists. Studies in Nonlinear Dynamics \& Econometrics 7(4).

Winker, P., Gilli, M., 2001. Indirect estimation of the parameters of agent based models of financial markets. FAME Research Paper, University of Geneva, number 38. 


\section{Table 1: Fundamental Value}

Values used for the fundamental process: $\pi$ is the average inflation rate, $y / p$ is the average cash flow yield $Y_{t} / P_{t-1}, g$ is the average growth rate of real cash flows (earnings are smoothed using a 10-years moving-average), $r=y / p+g$ is the discount rate, $i$ is the average real return on commercial paper, $R P=y / p+g-i$ is the risk premium, $R^{*}=(1+r) /(1+g)$ the gross rate of return and $m=(1+g) /(r-g)$ is the constant price-to cash-flow ratio in the Gordon model. We used the CPI index to deflate the nominal variables. All numbers, except $R^{*}$ and $m$ are expressed as percents, that is, they are multiplied by 100 .

\begin{tabular}{ccccccccc}
\hline \hline & $\pi$ & $y / p$ & $g$ & $r$ & $i$ & $R P$ & $R^{*}$ & $m$ \\
\hline Div. - 1871/1950 & 1.07 & 5.37 & 2.39 & 7.74 & 2.90 & 4.84 & 1.054 & 18.6 \\
Div. - 1951/2003 & 3.89 & 3.37 & 1.08 & 4.48 & 2.32 & 2.16 & 1.034 & 29.6 \\
Earn.- 1871/2003 & 2.24 & 7.46 & 1.56 & 9.13 & 2.57 & 6.56 & 1.074 & 13.4 \\
\hline \hline
\end{tabular}



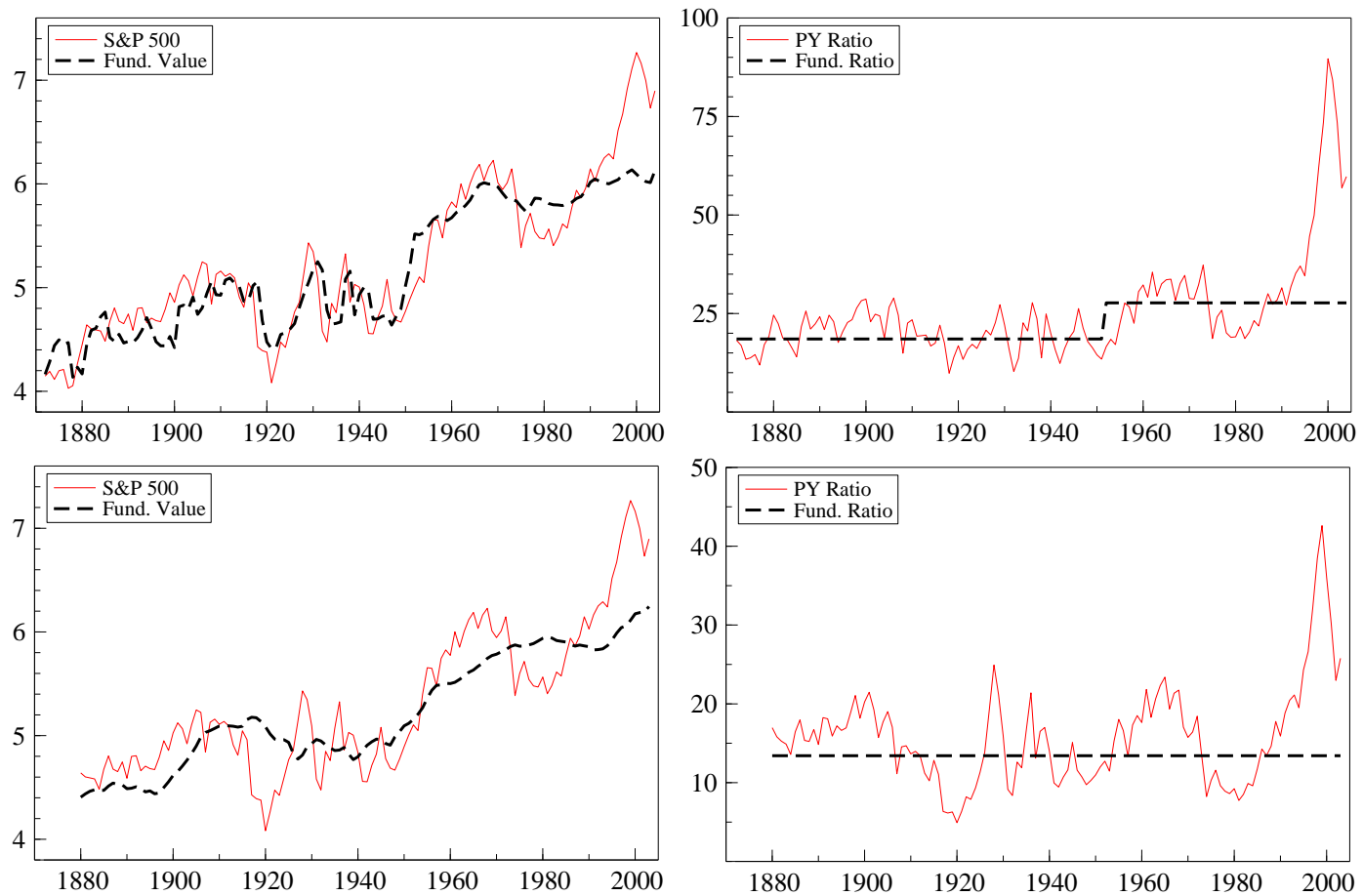

Figure 1: Stock Price and Fundamental Value: (left) Plots of the log of the stock price and of the fundamental value, and (right) the fundamental and realized Price-To-Cash Flow ratio. The top two graphs refer to cash flows measured by dividends while in the bottom graphs earnings are considered. The valuation approach used is the PVM model with constant cash flow growth rate and the discount rate given in Table (I). For earnings, we followed the practice of Campbell and Shiller (2001) to smooth them with a 10 years moving-average (consequently the series starts in 1880). 

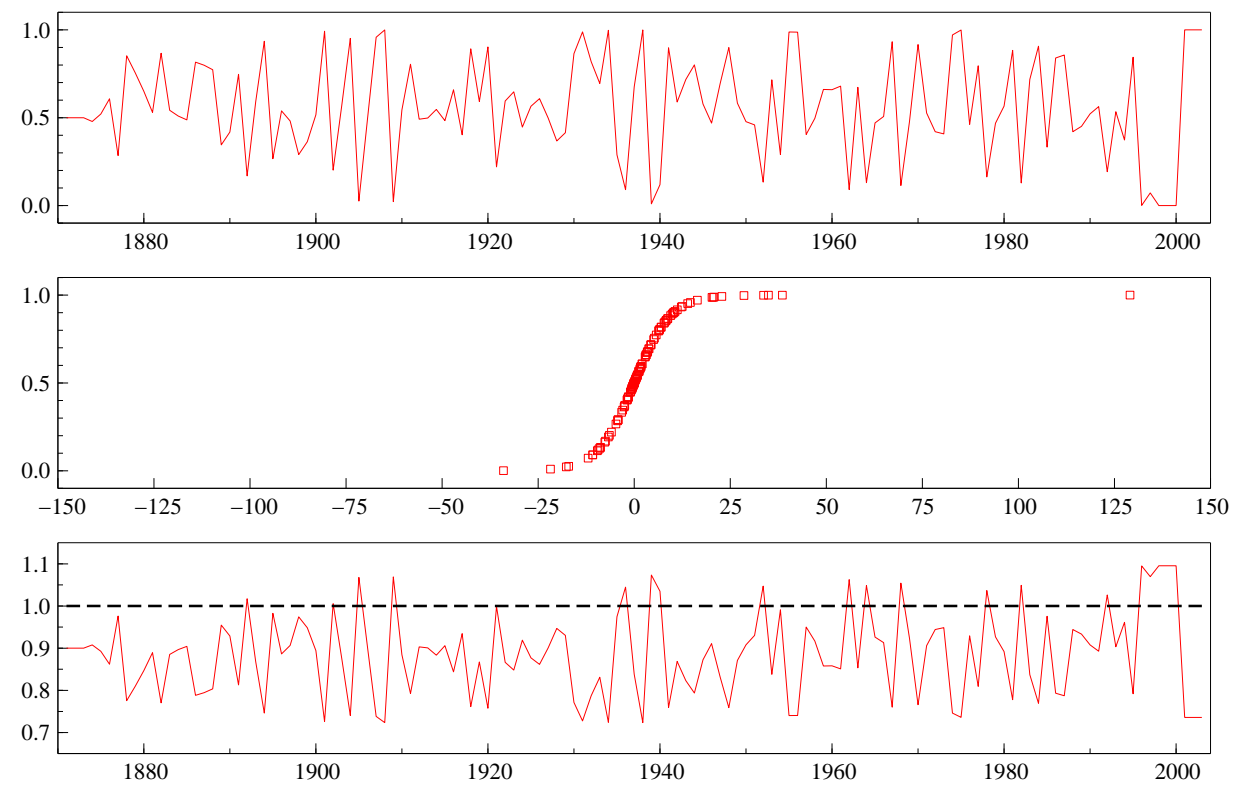

Figure 2: PD ratio: (top) Time series of the fraction of the investors' population using the mean reverting belief, $n_{t}$, (middle) the scatter plot of $n_{t}$ versus the difference in realized profits $\Delta \pi_{t-1}$, and (bottom) the series of the average market sentiment coefficient given by $\phi_{t}=\left\{n_{t} \phi_{1}+\left(1-n_{t}\right) \phi_{2}\right\} / R^{*}$.
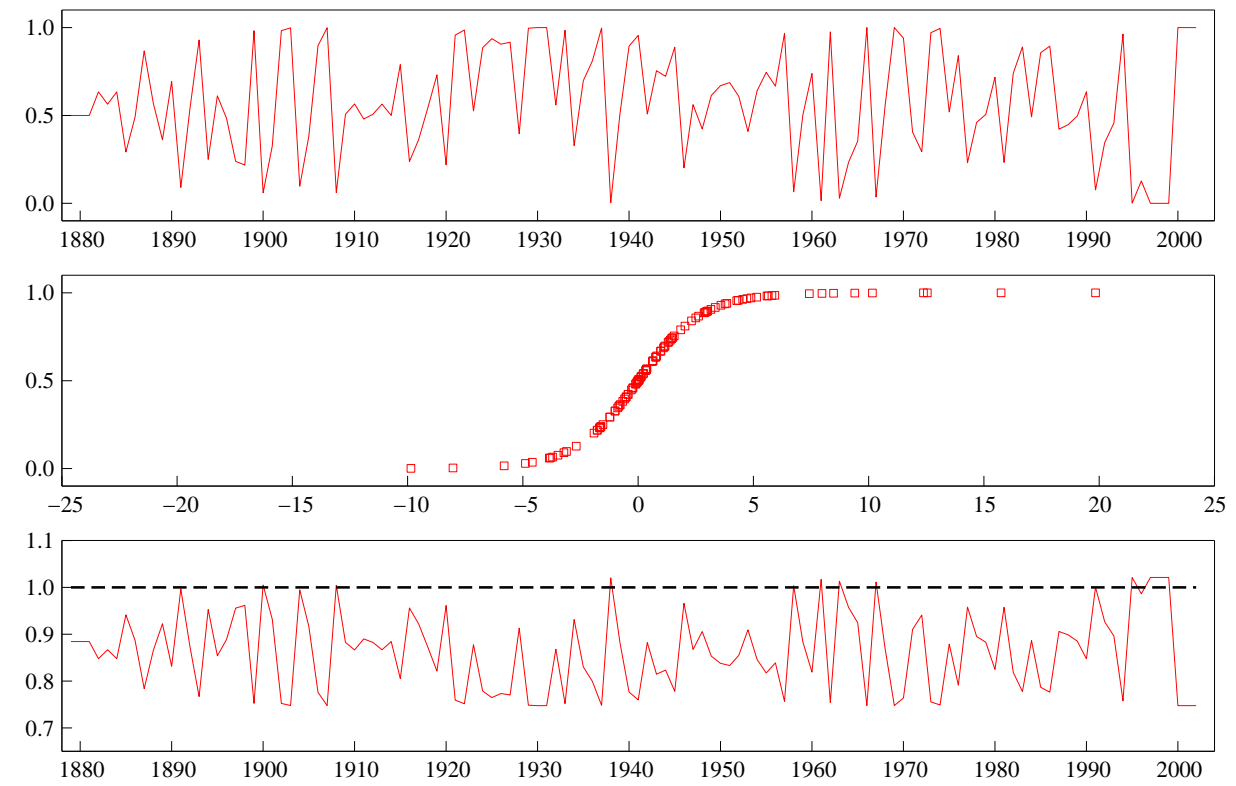

Figure 3: PE ratio: (top) Time series of the fraction of the investors' population using the mean reverting belief, $n_{t}$, (middle) the scatter plot of $n_{t}$ versus the difference in realized profits $\Delta \pi_{t-1}$, and (bottom) the series of the average market sentiment coefficient given by $\phi_{t}=\left\{n_{t} \phi_{1}+\left(1-n_{t}\right) \phi_{2}\right\} / R^{*}$. 


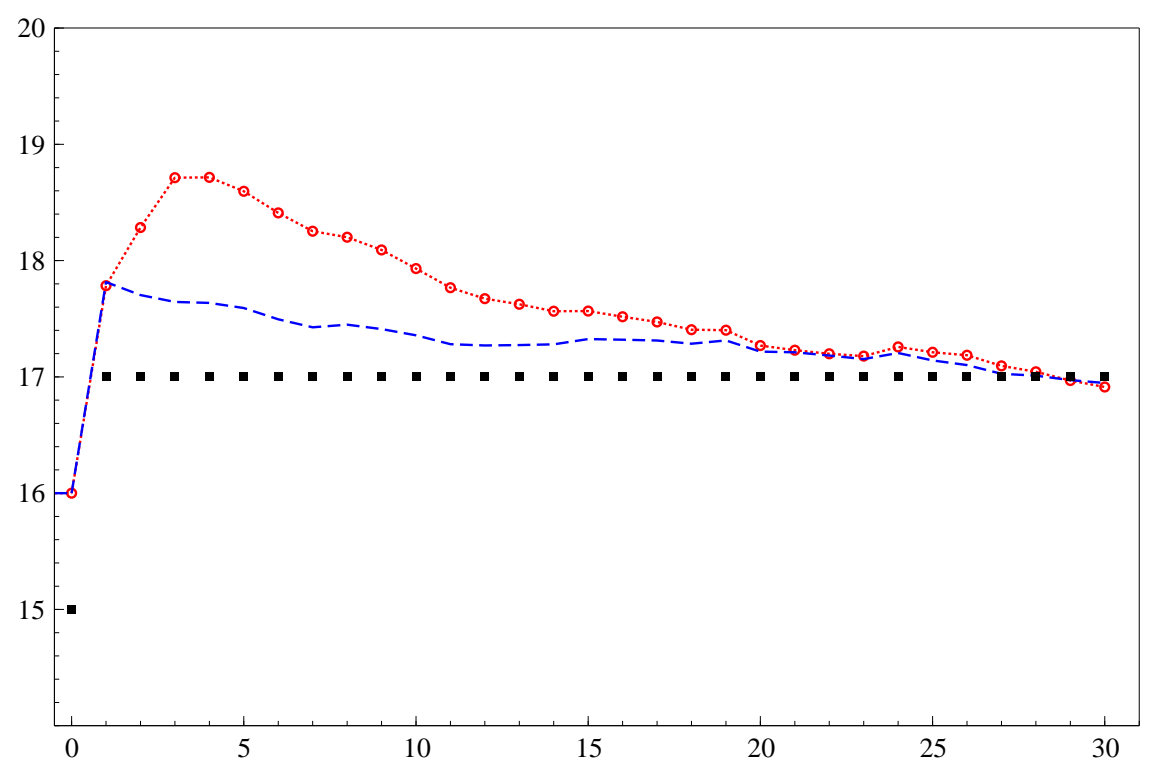

Figure 4: Response function: Response of the Price-to-Cash Flow Ratio to positive news about the fundamental value (black squares) in the case of an overvalued asset for the linear model (dotted line) and the nonlinear heterogeneous agent model (circles). The parameters used in the simulation are those estimated for the PD ratio. The plotted response are averages over 2000 simulations.
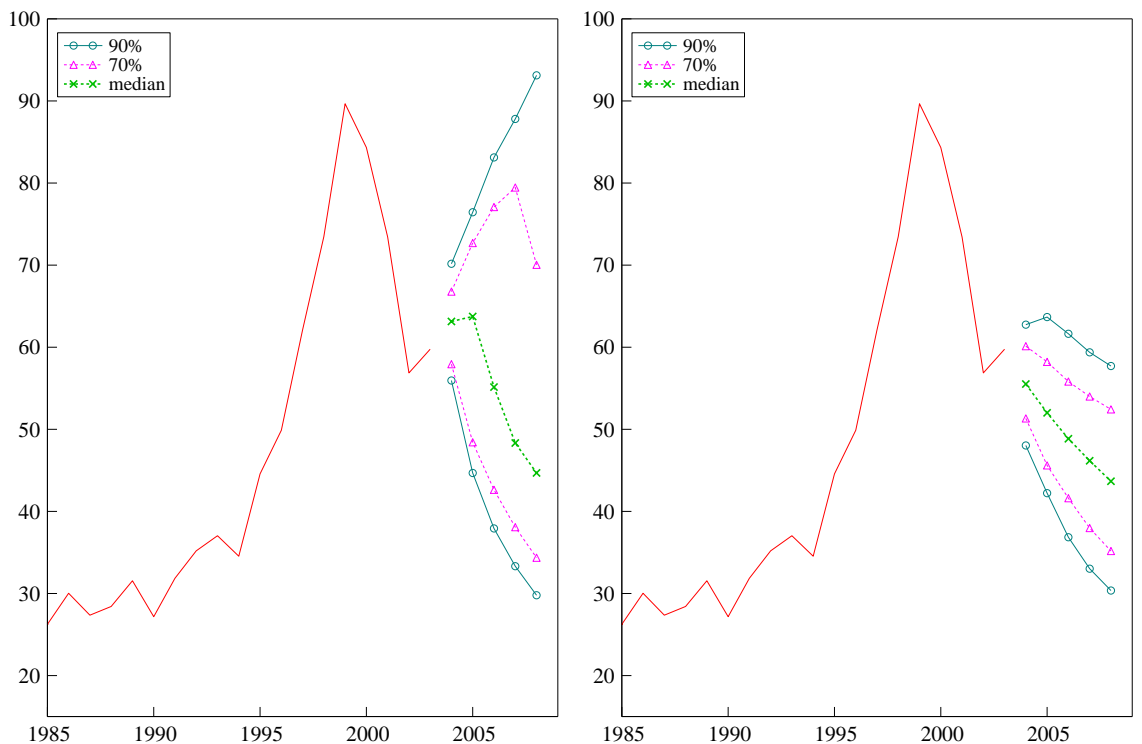

Figure 5: Predictive Distribution (PD Ratio): Simulated paths conditional on the realization of the PD ratio at the end of 2003. Each line represents a quantile of the predictive distribution for the nonlinear heterogeneous agent model (left) and the linear representative agent model (right). 

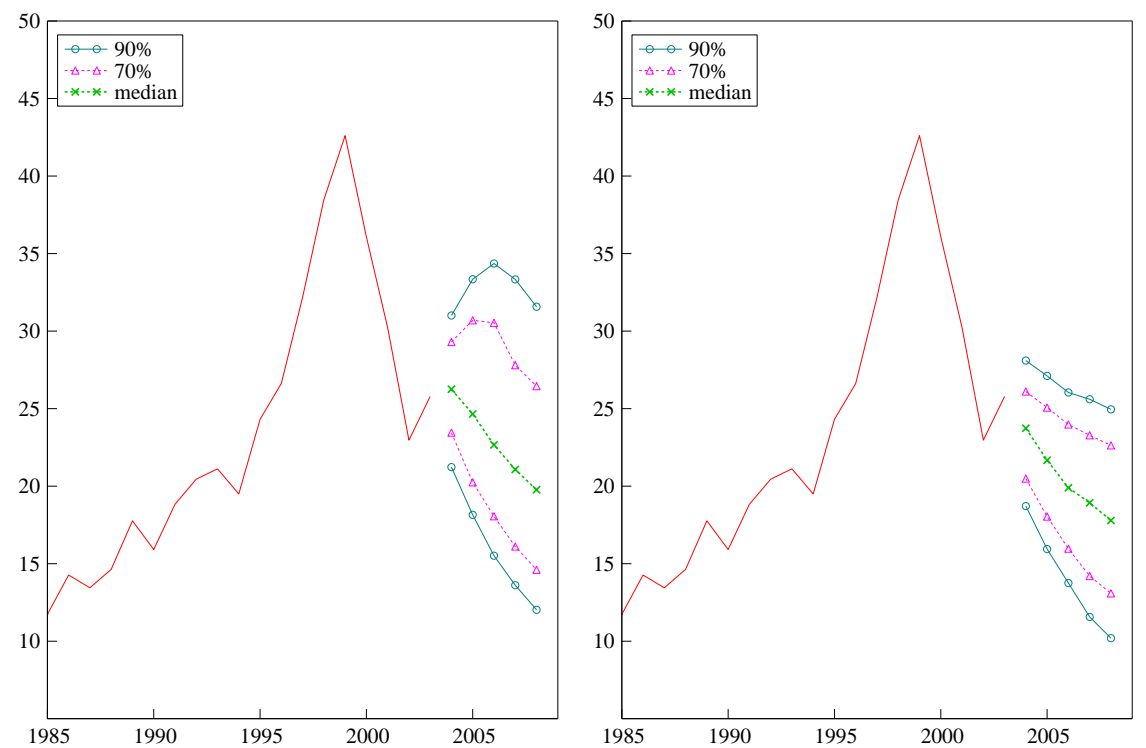

Figure 6: Predictive Distribution (PE Ratio): Simulated paths conditional on the realization of the PE ratio at the end of 2003. Each line represents a quantile of the predictive distribution for the nonlinear heterogeneous agent model (left) and the linear representative agent model (right).
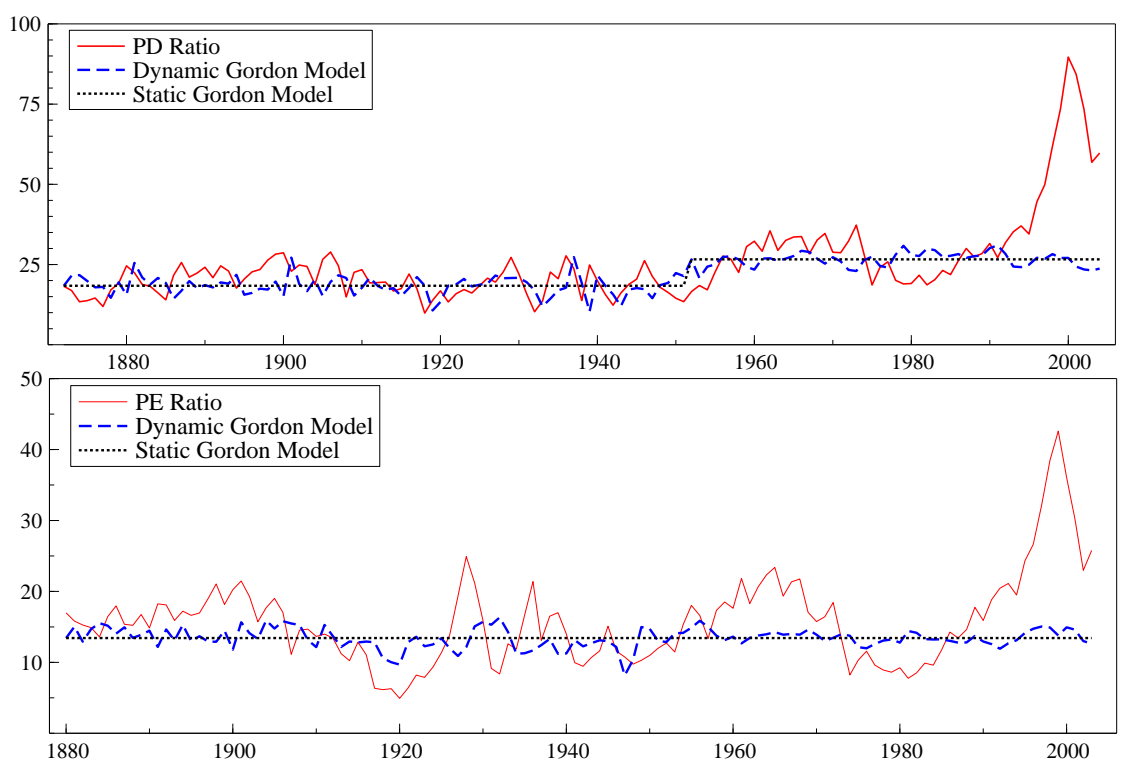

Figure 7: The Price-to-Cash Flow Ratio and the fundamental value implied by the static and dynamic Gordon model. For the PD ratio we consider a break in the risk premium in 1950 and also a change in persistence of the cash flow growth process. For the PE ratio we compare the static case - with constant discount rate and earnings growth rate - with the dynamic one - earnings growth rate is allowed to vary over time. 